OPEN ACCESS

Edited by:

Dieter Wicher,

Max Planck Institute for Chemical

Ecology, Germany

Reviewed by:

Enrique Lanuza,

University of Valencia, Spain

Gustavo Pacheco-Lopez,

Universidad Autónoma Metropolitana

Unidad Lerma, Mexico

*Correspondence:

Jian-Xu Zhang

zhangjx@ioz.ac.cn

Liquan Huang

huangliquan@zju.edu.cn

Specialty section:

This article was submitted to

Cellular Neurophysiology,

a section of the journa

Frontiers in Cellular Neuroscience

Received: 23 July 2019 Accepted: 24 September 2019

Published: 02 October 2019

Citation:

Liu Q, Zhang Y, Wang P, Guo X, Wu Y, Zhang J-X and Huang L (2019)

Two Preputial Gland-Secreted

Pheromones Evoke Sexually

Dimorphic Neural Pathways

in the Mouse Vomeronasal System.

Front. Cell. Neurosci. 13:455.

doi: 10.3389/fncel.2019.00455

\section{Two Preputial Gland-Secreted Pheromones Evoke Sexually Dimorphic Neural Pathways in the Mouse Vomeronasal System}

\author{
Qun Liu', Yaohua Zhang ${ }^{2}$, Pan Wang'2, Xiao Guo'2, Yijun $W^{2}{ }^{2}$, Jian-Xu Zhang ${ }^{2 *}$ and \\ Liquan Huang ${ }^{1,3 *}$
}

\footnotetext{
${ }^{1}$ College of Life Sciences, Zhejiang University, Hangzhou, China, ${ }^{2}$ State Key Laboratory of Integrated Management of Pest Insects and Rodents in Agriculture, Institute of Zoology, Chinese Academy of Sciences, Beijing, China, ${ }^{3}$ Monell Chemical Senses Center, Philadelphia, PA, United States
}

Hexadecanol $(16 \mathrm{OH})$ and hexadecyl acetate $(16 \mathrm{Ac})$ are two pheromones secreted in a large quantity by mouse preputial glands and act on male and female mice differentially. Yet the underlying molecular and cellular mechanisms remain to be elucidated. In this study, we examined the activation of vomeronasal sensory neurons (VSNs) by these two pheromones and mapped the downstream neural circuits that process and relay their chemosignals. Using the calcium imaging method and immunohistochemistry, we found that a small number of VSNs were activated by $16 \mathrm{OH}, 16 \mathrm{AC}$, or both in the male and female mice, most of which were located apically in the vomeronasal epithelium, and their numbers did not increase when the concentrations of $160 \mathrm{H}$ and $16 \mathrm{Ac}$ were raised by 10,000 -fold except that of female VSNs in response to $160 \mathrm{H}$. In the accessory olfactory bulb (AOB), the two pheromones evoked more c-Fos+ neurons in the anterior $\mathrm{AOB}(\mathrm{aAOB})$ than in the posterior $\mathrm{AOB}(\mathrm{pAOB})$; and the increases in the number of c-Fos+ neurons in both $\mathrm{aAOB}$ and $\mathrm{pAOB}$ were dose-dependent; and between sexes, the female $\mathrm{AOB}$ responded more strongly to $16 \mathrm{OH}$ than to $16 \mathrm{Ac}$ whereas the male AOB had the opposite response pattern. This sexual dimorphism was largely retained in the downstream brain regions, including the bed nucleus of the stria terminalis (BNST), the medial amygdaloid nucleus (MeA), the posteromedial cortical amygdaloid nucleus (PMCo), the medial preoptic area (MPA), and the ventromedial hypothalamic nucleus $(\mathrm{VmH})$. Taken together, out data indicate that there is one $\mathrm{V} 1 \mathrm{r}$ receptor each for $160 \mathrm{H}, 16 \mathrm{Ac}$, or both, and that activation of these receptors evokes sexually dimorphic neural circuits, directing different behavioral outputs and possibly modulating other pheromone-induced responses.

Keywords: hexadecanol, hexadecyl acetate, vomeronasal organ, calcium imaging, c-Fos, neural circuits 


\section{INTRODUCTION}

The term "pheromone" has been used to describe the chemicals used for intra-species communications (Karlson and Luscher, 1959). These chemicals can convey information about conspecific members' social status, sexual maturation, and receptiveness, and can also trigger sexual behaviors, pregnancy block, inter-male or infant-directed aggression, and parental caring (LeindersZufall et al., 2000, 2004; Brennan and Zufall, 2006; Brechbühl et al., 2011; Liberles, 2014; Isogai et al., 2018; Mohrhardt et al., 2018). Since the first pheromones were identified in insects, many more have been found across the animal kingdom (Liberles, 2014). In mammals, rodents have been the best studied model animals, which emit pheromones through feces, urine, saliva, tear, and other bodily fluids that are produced by such glands as preputial and lacrimal glands (Novotny, 2003; Zhang et al., 2008; Brechbühl et al., 2011). However, the number of molecularly identified pheromones is still limited in mammals, including proteins and peptides, e.g., the major urinary proteins (MUPs) (Hurst et al., 2001), major histocompatibility complex (MHC) class I peptides (Sturm et al., 2013), exocrine gland-secreting peptides (ESPs) (Kimoto et al., 2005; Osakada et al., 2018), as well as more volatile compounds such as bile acids and steroids, e.g., 2,5-dimethylpyrazine, 3,4-dehydro-exo-brevicomin, 2,3-dehydro-exo-brevicomin, 2heptanone, 6-hydroxy-6-methyl-3-heptanone (HMH), 2-secbutyl-4,5-dihydrothiazole (SBT), $\alpha / \beta$-farnesene, and sulfated sex hormones (Novotny et al., 1990, 1999; Brennan and Zufall, 2006; Haga-Yamanaka et al., 2014; Doyle et al., 2016). Naturally produced pheromones, however, are often mixtures, of which the ratios of these different components are also important to evoking the receivers' behavioral responses. Identifying additional semiochemicals and their blends is indeed necessary to fully understand pheromone physiology.

The pheromones are detected mainly by the sensory neurons in the vomeronasal organs ( $\mathrm{VNO}$ ) that are located at the anterior bottom of murine nasal cavity. Unlike the olfactory epithelium of the main olfactory system (MOS), the vomeronasal epithelium (VSE) can be largely divided into apical and basal layers whereas the basal layer can be further divided into two sublayers (Munger et al., 2009; Leinders-Zufall et al., 2014; Liberles, 2014; Akiyoshi et al., 2018). And the vomeronasal sensory neurons (VSNs) in each layer express different pheromone receptors and signaling proteins: in mice, each apical VSN expresses one formyl peptide receptor (FPR) or 1 of the 239 potentially functional V1r receptors in a monoallelic fashion as well as the G-protein $\alpha$-subunit $\mathrm{G} \alpha_{\mathrm{i} 2}$ whereas each basal VSN expresses two of 121 functional V2rs, both in monoallelic fashion, along with the G-protein $\alpha$-subunit $\mathrm{G} \alpha_{0}$ (Zhang et al., 2004; Young and Trask, 2007; Riviere et al., 2009; Young et al., 2010; Akiyoshi et al., 2018). Among these 360 murine V1rs and V2rs, few have been deorphanized, largely due to the difficulty in heterologously expressing these receptors. Nevertheless, the information about the interactions between these receptors and their ligands is critical to revealing the subsequent pheromone information processing in the central neural circuits, and subsequently to determining the behavioral outcome (Keverne, 1999; Dulac and
Torello, 2003; Halpern and Martınez-Marcos, 2003; LeindersZufall et al., 2004; Munger et al., 2009; Touhara and Vosshall, 2009; Liberles, 2014).

The anatomic division in the VSE is maintained when apical and basal VSNs project their axons to the anterior and posterior portions of the accessory olfactory bulb (AOB), respectively (Keverne, 1999; Halpern and Martınez-Marcos, 2003; LeindersZufall et al., 2004; Brennan and Zufall, 2006). Unlike in the main olfactory bulb (MOB) where the axons of olfactory sensory neurons expressing the same olfactory receptors converge onto one or two glomeruli, individual axons of VSNs can branch out in the $\mathrm{AOB}$, innervating multiple glomeruli. Conversely, each glomerulus can be innervated by axons expressing different vomeronasal receptors, resulting in the glomeruli of variable sizes correlating to the numbers of afferent VSN fibers. This structural feature may indicate that chemosensory information is more intensively processed in the $\mathrm{AOB}$ than in the MOB before being relayed to the downstream circuits in the brain (Belluscio et al., 1999; Wagner et al., 2006).

In the mouse brain, two areas in the limbic system receive signals from mitral cells of the AOB: the bed nucleus of the stria terminalis (BNST) and the vomeronasal amygdala while the latter consists of the medial amygdaloid nucleus (MeA) and the posteromedial amygdaloid cortical nucleus (PMCo). Neurons from these nuclei further project to the hypothalamic nuclei including the medial preoptic area (MPA) and the ventromedial hypothalamus $(\mathrm{VmH})$, which sends out the output signals directing physiological and behavioral responses (Halem et al., 1999; Halpern and Martinez-Marcos, 2003; Brennan and Zufall, 2006; Dulac and Wagner, 2006; Haga et al., 2010; Szymanski and Keller, 2014). Up till now, however, very few pheromones' neural circuits have been mapped out (Dulac and Torello, 2003; Brennan and Zufall, 2006; Ishii et al., 2017; Wei et al., 2018). And even more complicated is that the accessory olfactory system (AOS) may also be plastic and can be modulated by learning and internal physiological states (Kaur et al., 2014; Xu et al., 2016). Thus, more thorough studies are needed to elucidate the AOS circuits beyond those merely eliciting the stereotyped responses.

Hexadecanol $(16 \mathrm{OH})$ and hexadecyl acetate (16Ac) are two pheromones initially identified from insects, and later found to be produced in a substantial quantity by murine preputial glands (McElfresh et al., 2001; Zhang et al., 2008). Male mice, which produce more of these two pheromones than females, show some attraction to them at low concentrations but display aversion to concentrated ones while female mice are indifferent to low concentrations but attractive to high concentrations of these two pheromones; and these sex-specific responses are VNO-dependent, and probably mediated by the AOS (Zhang et al., 2008). However, the exact molecular and cellular mechanisms underlying their detection in the VNO and information processing in the central circuits remain to be revealed. In this study, we utilized calcium imaging to identify the VSNs responsible for the $16 \mathrm{OH}$ and 16Ac detection, and c-Fos immunohistochemistry to identify activated neurons in the central nuclei including those in the AOB, BNST, PMCo, MeA, MPA, and VmH that make up the AOS neural circuits. Our data provide new insights into the underlying molecular and 


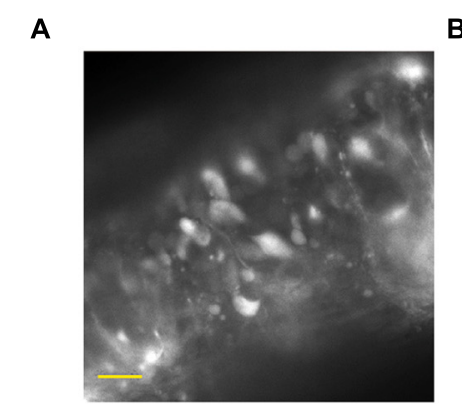

B

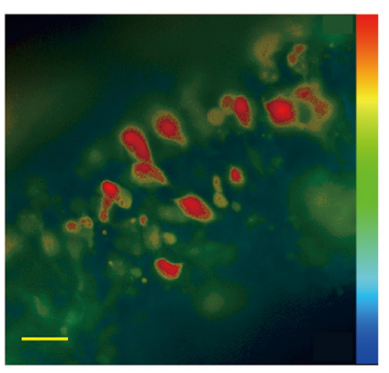

D

rest $16 \mathrm{OH}$

$16 \mathrm{Ac}$

$\mathrm{KCl}$

cell 1

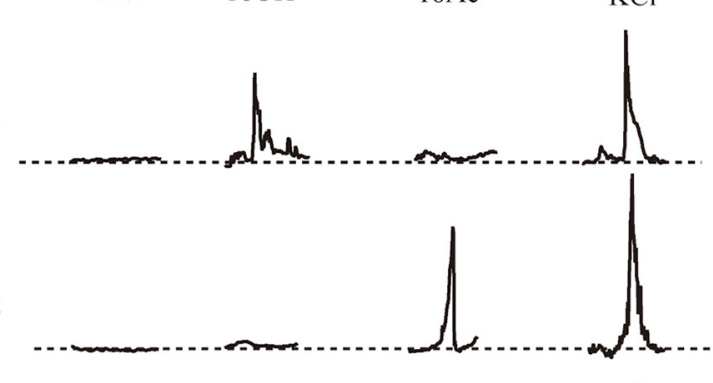

cell 3

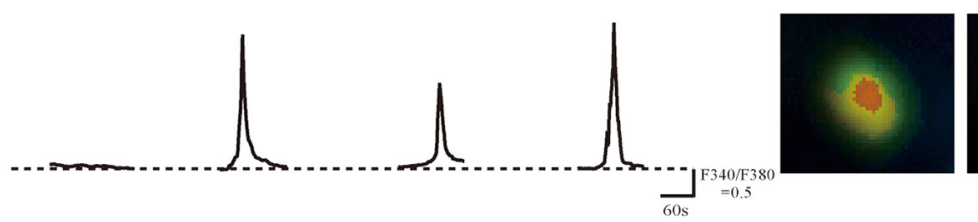

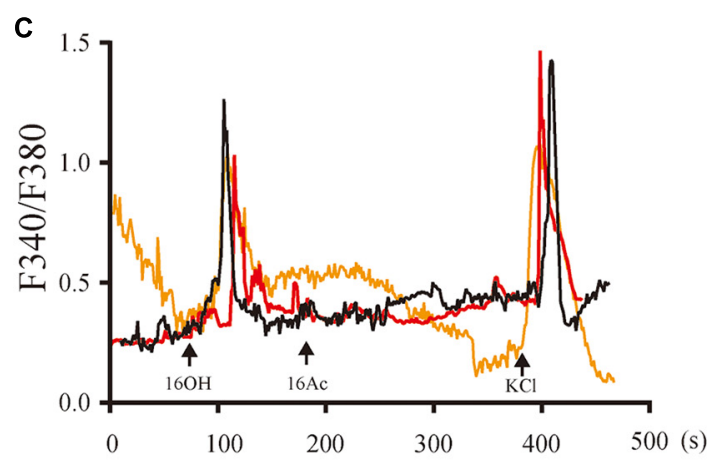
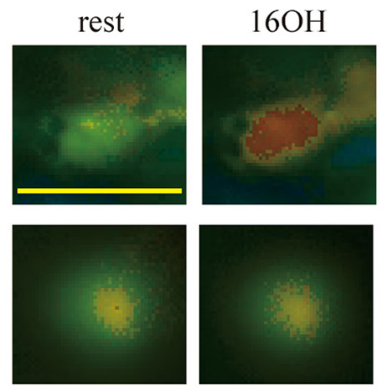

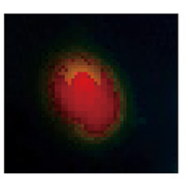

$16 \mathrm{OH}$
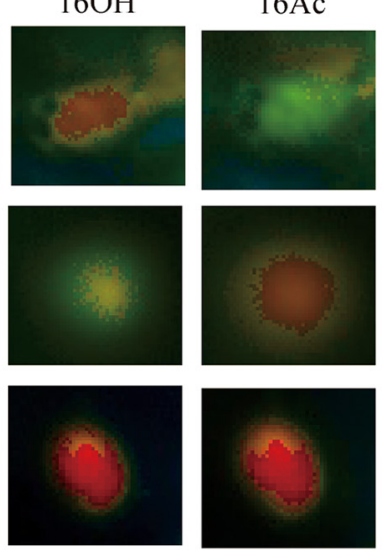

$\mathrm{KCl}$
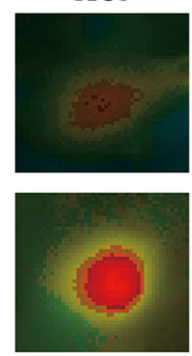

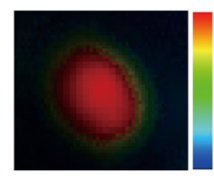

FIGURE 1 | The pheromones evoke responses of intracellular $\mathrm{Ca}^{2+}$ elevation from single vomeronasal sensory neurons. (A,B) Fluorescence images on gray and pseudocolor scales, respectively, acquired from a VNO slice loaded with fura-2-AM. The somata of the VSNs contained most of the calcium-sensitive dye. (C) Traces of three VSNs responsive to $100 \mu \mathrm{M} \mathrm{16OH}$ and KCl (50 mM) but not to $100 \mu \mathrm{M} 16 \mathrm{Ac}$ over a period of 8 min. (D) Left: Response profiles of three representative VSNs: cell 1 responded to $16 \mathrm{OH}$ alone, cell 2 to $16 \mathrm{Ac}$ alone, and cell 3 to both; Right: the corresponding Fura-2 ratio images of the three VSNs. KCl (50 mM) was used as a positive control. Scale bar: $20 \mu \mathrm{m}$.

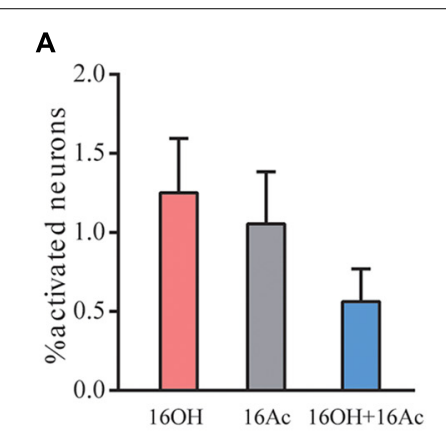

Low concentration

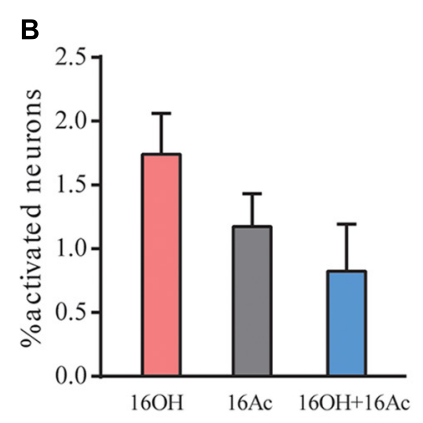

High concentration

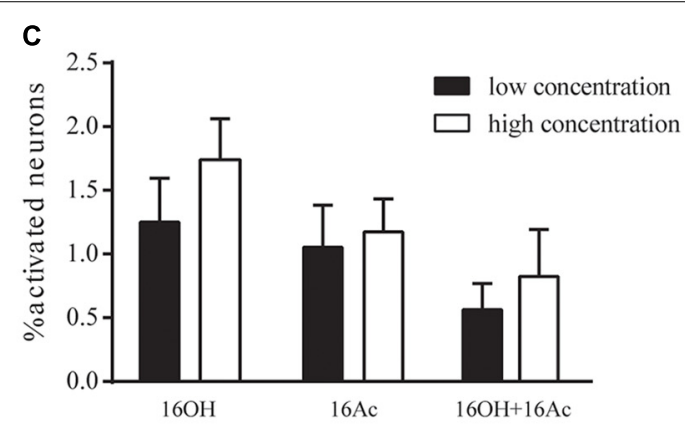

FIGURE 2 | Male VSNs respond similarly to $160 \mathrm{H}$ and $16 \mathrm{OHAc}$ at both low and high concentrations. (A) Comparison of the percentages of male VSNs responsive to $16 \mathrm{OH}$ and $16 \mathrm{Ac}$ at a low concentration $(10 \mathrm{nM})$. Out of 1175 cells examined, 14 responded to $16 \mathrm{OH}, 11$ to $16 \mathrm{Ac}, 7$ to both $16 \mathrm{OH}$ and $16 \mathrm{Ac}$; and no statistically significant difference was found among them (M-L-16OH vs. M-L-16Ac, $t=0.383, p=1.000$; $\mathrm{M}-\mathrm{L}-16 \mathrm{OH}$ vs. M-L-16OH+M-L-16Ac, $t=1.338, p=1.000$;

M-L-16Ac vs. M-L-16OH+M-L-16Ac, $t=0.956, p=1.000$ ). (B) Comparison of the percentages of male VSNs responsive to $160 \mathrm{H}$ and $16 \mathrm{Ac}$ at a high concentration $(100 \mu \mathrm{M})$. Out of 988 cells examined, 17 responded to $16 \mathrm{OH}, 11$ to $16 \mathrm{Ac}, 8$ to both $16 \mathrm{OH}$ and $16 \mathrm{Ac}$; and no statistically significant difference was found among them $(\mathrm{M}-\mathrm{H}-16 \mathrm{OH}$ vs. $\mathrm{M}-\mathrm{H}-16 \mathrm{Ac}, t=1.1, p=1.000 ; \mathrm{M}-\mathrm{H}-16 \mathrm{OH}$ vs. $\mathrm{M}-\mathrm{H}-16 \mathrm{OH}+\mathrm{M}-\mathrm{H}-16 \mathrm{Ac}, t=1.784, p=1.000 ; \mathrm{M}-\mathrm{H}-16 \mathrm{Ac}$ vs. $\mathrm{M}-\mathrm{H}-16 \mathrm{OH}+\mathrm{M}-\mathrm{H}-16 \mathrm{Ac}, t=0.683$, $p=1.000$ ). (C) Comparison analysis of the male VSNs responsive to the low and high concentrations of the pheromones. No significant difference was found between the responses to the low and high concentrations of the same pheromones in male mice $(\mathrm{M}-\mathrm{H}-16 \mathrm{OH}$ vs. M-L-16OH, $t=0.953, p=1.000 ; \mathrm{M}-\mathrm{H}-16 \mathrm{Ac}$ vs. $\mathrm{M}-\mathrm{L}-16 \mathrm{Ac}, t=0.236, p=1.000 ; \mathrm{M}-\mathrm{H}-16 \mathrm{OH}+\mathrm{M}-\mathrm{H}-16 \mathrm{Ac}$ vs. M-L-16OH+M-L-16Ac, $t=0.508, p=1.000)$. All values are expressed as mean $\pm \mathrm{s} . e . \mathrm{m}$. 


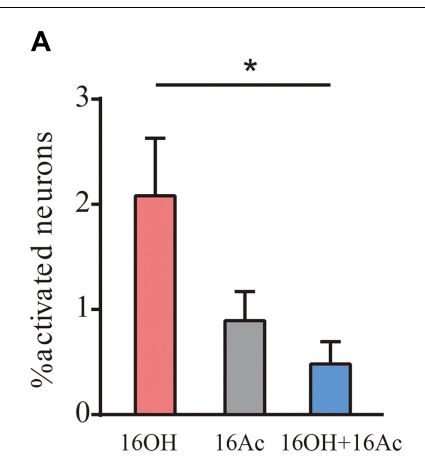

Low concentration

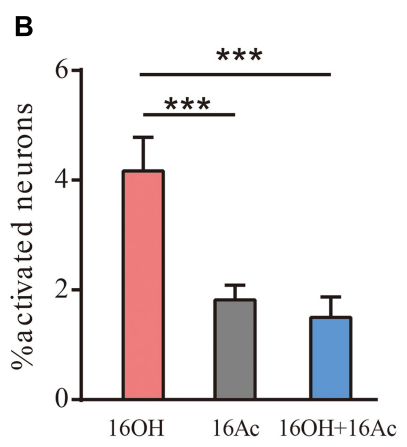

High concentration
C

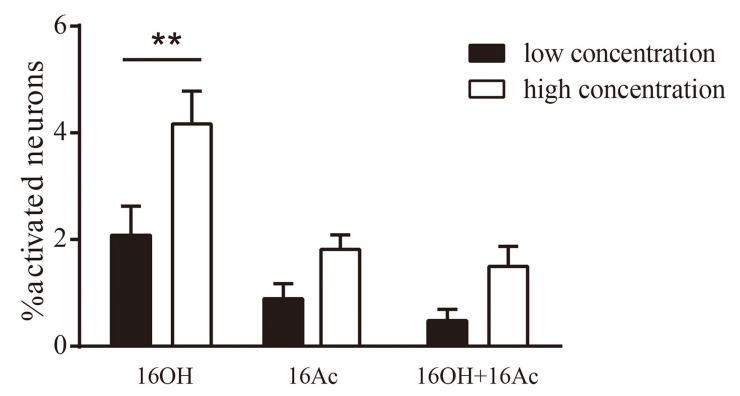

FIGURE 3 | Female VSNs respond differently to $160 \mathrm{H}$ and $16 \mathrm{Ac}$. (A) Comparison of the percentages of female VSNs responsive to $16 \mathrm{OH}$ and $16 \mathrm{Ac}$ at $10 \mathrm{nM}$. Out of 1168 cells examined, 23 responded to $\mathrm{L}-16 \mathrm{OH}, 10$ to $\mathrm{L}-16 \mathrm{Ac}$, and 6 to both. Significantly more cells responded to $\mathrm{L}-16 \mathrm{OH}$ than to both; and no significant differences in the numbers of cells responsive to $\mathrm{L}-16 \mathrm{OH}$ versus to $\mathrm{L}-16 \mathrm{Ac}$ or to $\mathrm{L}-16 \mathrm{Ac}$ versus to both were found $(\mathrm{F}-\mathrm{L}-16 \mathrm{OH}$ vs. $\mathrm{F}-\mathrm{L}-16 \mathrm{Ac}, t=2.311, p=0.341$; F-L-16OH vs. F-L-16OH + F-L-16Ac, $t=3.116, p=0.035$; F-L-16Ac vs. F-L-16OH + F-L-16Ac, $t=0.805, p=1.000)$. (B) Comparison of the percentages of female VSNs responsive to $16 \mathrm{OH}$ and $16 \mathrm{Ac}$ at $100 \mu \mathrm{M}$. Out of 964 cells examined, 41 responded to $\mathrm{H}-16 \mathrm{OH}, 17$ to $\mathrm{H}-16 \mathrm{Ac}$, and 16 to both. Cells responsive to $\mathrm{H}-16 \mathrm{OH}$ were significantly more than those to $\mathrm{H}-16 \mathrm{Ac}$ or both but no significant difference was found between cells responsive to $\mathrm{H}-16 \mathrm{Ac}$ versus both $(\mathrm{F}-\mathrm{H}-16 \mathrm{OH}$ v. $\mathrm{F}-\mathrm{H}-16 \mathrm{Ac}, t=4.573, p=0.000 ; \mathrm{F}-\mathrm{H}-16 \mathrm{OH}$ vs. F-H-16OH + F-H-16Ac, $t=5.196, p=0.000 ; \mathrm{F}-\mathrm{H}-16 \mathrm{Ac}$ vs. $\mathrm{F}-\mathrm{H}-16 \mathrm{OH}+\mathrm{F}-\mathrm{H}-16 \mathrm{Ac}, t=0.623, p=1.000)$. (C) Comparative analysis of the female VSNs responsive to the same pheromones at different concentrations. More female $\mathrm{VSN}$ s responded to $\mathrm{H}-16 \mathrm{OH}$ than to $\mathrm{L}-16 \mathrm{OH}$ whereas no significant differences were found between cell numbers responsive to $\mathrm{H}$ - versus to $\mathrm{L}-16 \mathrm{Ac}$ or between those to both $\mathrm{H}$ - $16 \mathrm{OH}$ and $\mathrm{H}-16 \mathrm{Ac}$ versus both $\mathrm{L}-16 \mathrm{OH}$ and $\mathrm{L}-16 \mathrm{Ac}(\mathrm{F}-\mathrm{H}-16 \mathrm{OH}$ vs. F-L-16OH, $t=4.062, p=0.001$; F-H-16Ac vs. F-L-16Ac, $t=1.800, p=1.000 ; \mathrm{F}-\mathrm{H}-16 \mathrm{OH}+\mathrm{F}-\mathrm{H}-16 \mathrm{Ac}$ vs. $\mathrm{F}-\mathrm{L}-16 \mathrm{OH}+\mathrm{F}-\mathrm{L}-16 \mathrm{Ac}, t=1.982, p=0.751)$. All values are expressed as mean \pm s.e.m. ${ }^{*} p<0.05,{ }^{* *} p<0.01,{ }^{* * *} p<0.001$

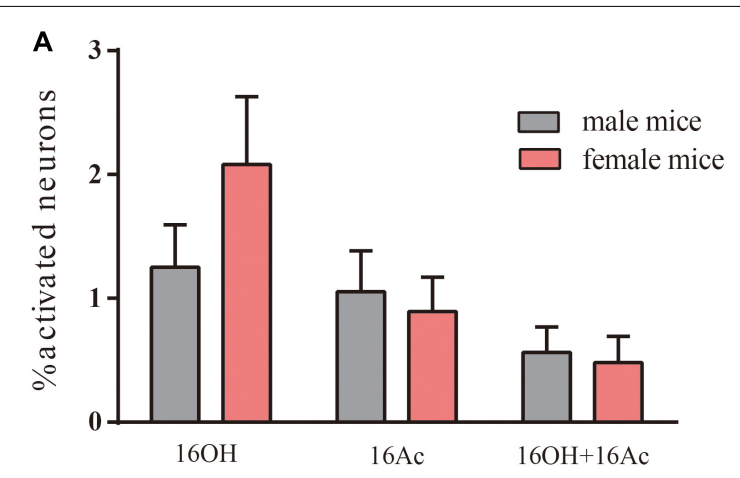

Low concentration

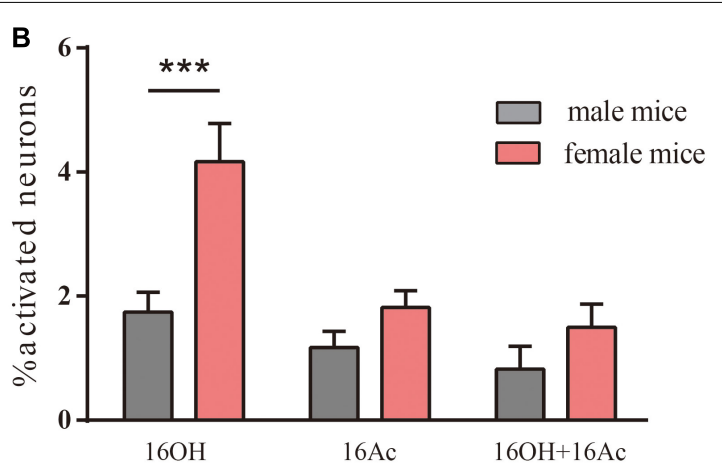

High concentration

FIGURE 4 | The differences in responsivity between male and female mice. (A) No significant differences were found between the numbers of male versus female VSNs responsive to L-16OH, L-16Ac, or both at a low concentration (10 nM) (M-L-16OH vs. F-L-16OH, $t=1.618, p=0.109 ; \mathrm{M}-\mathrm{L}-16 \mathrm{Ac}$ vs. F-L-16Ac, $t=0.310$, $p=0.757 ; \mathrm{M}-\mathrm{L}-16 \mathrm{OH}+\mathrm{M}-\mathrm{L}-16 \mathrm{Ac}$ vs. F-L-16OH + F-L-16Ac, $t=0.160, p=0.873)$. (B) Significantly more female VSNs responded to $\mathrm{H}-16 \mathrm{OH}$ than male $\mathrm{VSN}$ whereas no significant differences were found between the numbers of male and female responsive cells to $\mathrm{H}-16 \mathrm{Ac}$ or to both (100 $\mu \mathrm{M})(\mathrm{M}-\mathrm{H}-16 \mathrm{OH}$ vs. $\mathrm{F}-\mathrm{H}-16 \mathrm{OH}$, $t=4.726, p=0.000 ; \mathrm{M}-\mathrm{H}-16 \mathrm{Ac}$ vs. F-H-16Ac, $t=1.254, p=0.213 ; \mathrm{M}-\mathrm{H}-16 \mathrm{OH}+\mathrm{M}-\mathrm{H}-16 \mathrm{Ac}$ vs. $\mathrm{F}-\mathrm{H}-16 \mathrm{OH}+\mathrm{F}-\mathrm{H}-16 \mathrm{Ac}, t=1.314, p=0.192)$. All values are expressed as mean \pm s.e.m. ${ }^{* * *} p<0.001$.

cellular mechanisms of the $16 \mathrm{OH}$ - and 16Ac-directed dimorphic behavioral outputs.

\section{MATERIALS AND METHODS}

\section{Animals}

All the mice used in the experiments are 8-10 weeks old CD-1 mice. A total of 118 mice were used in this study: 5 male and 5 female mice were used for the VNO calcium imaging experiment; 24 male and 24 female mice for the pheromone-induced VNO pS6 immunofluorescence experiment, and 30 male and 30 female mice for the brain c-Fos immunohistochemistry experiment. Male mice were housed individually whereas females were housed in groups of four with food and water available ad libitum. Female mice were examined to determine their estrous stages and only estrous mice were used in this study. Before exposure to the pheromones, subjects were housed individually under a reversed 14/10 h light/dark photoperiod (lights on at 7:00 pm) with food and water available ad libitum in a clean room and the experiments were carried out in the morning hours. All experiments with 


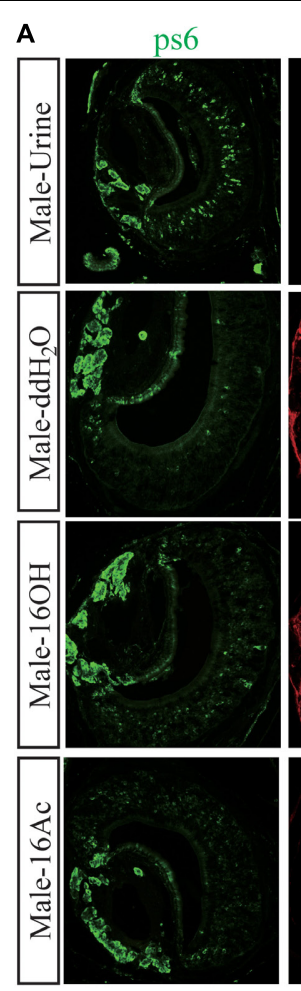

C

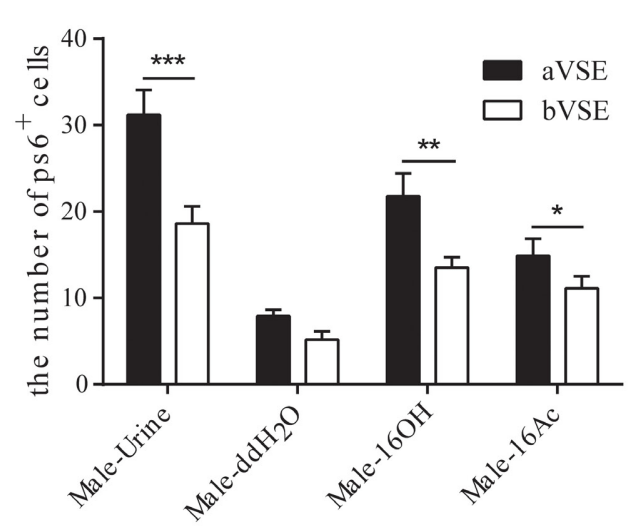

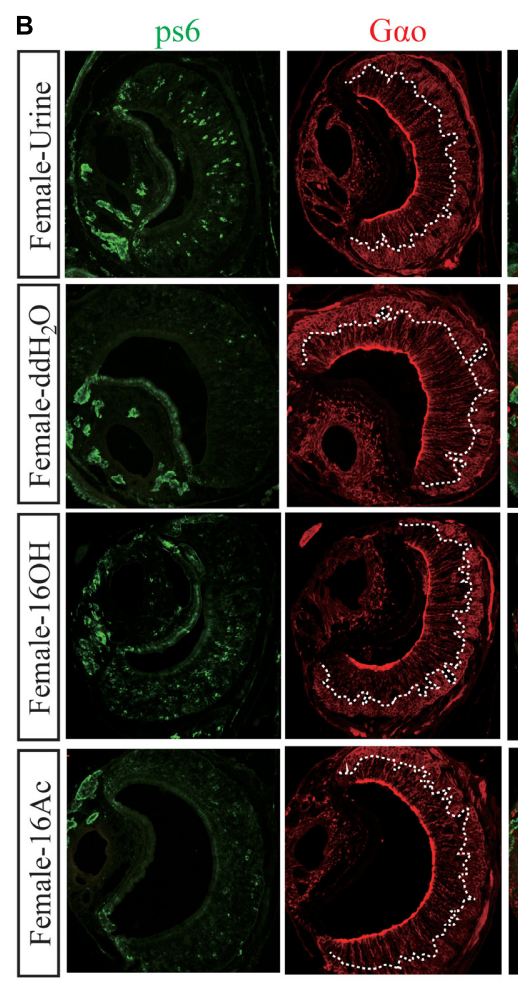

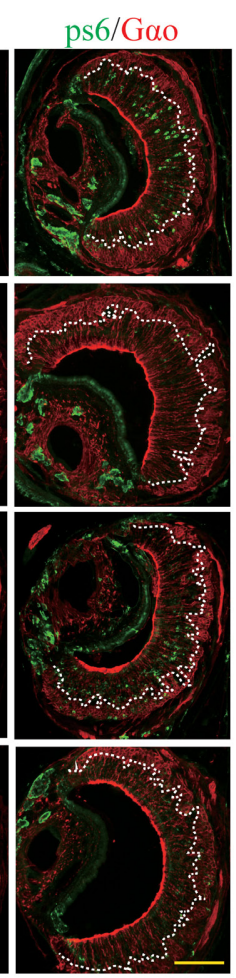

D

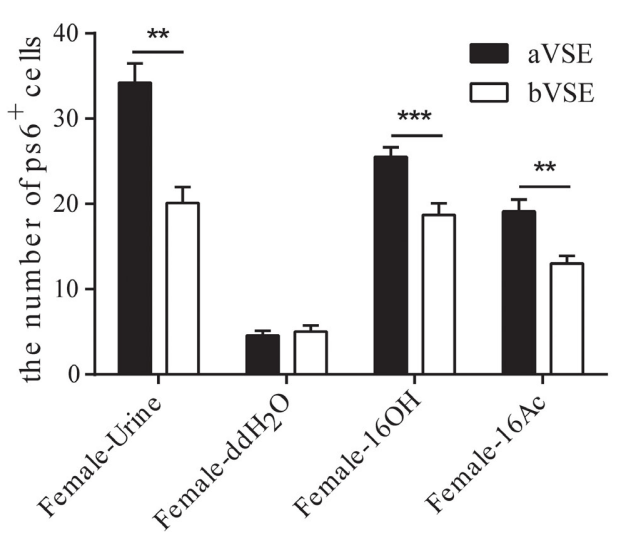

FIGURE 5 | Most responsive neurons are apical VSNs. (A,B) Images of anti-pS6 and anti-G $\alpha_{0}$ double immunostaining on male and female VNO sections, respectively, following the exposure to $100 \mu \mathrm{M} \mathrm{16OH}, 100 \mu \mathrm{M} 16 \mathrm{Ac}$, urine (positive control), or double distilled water containing $0.01 \% \mathrm{DCM}$ (dd $\mathrm{H}_{2} \mathrm{O}$, negative control). (C,D) Comparative analysis of the double immunostaining data from both the male and female VNO sections, respectively, showed that significantly more pS6-positive neurons were located in the apical VSE (aVSE) than in the basal VSE (bVSE) upon stimulation of urine, 16OH, or 16Ac (aVSE vs. bVSE: male-urine, $t=6.350, p=0.000$; male-16OH, $t=3.275, p=0.010$; male-16Ac, $t=2.604, p=0.029$; female-urine, $t=4.462, p=0.002 ;$ female-160H, $t=6.464, p=0.000$; female-16Ac, $t=4.620, p=0.001)$. All values are expressed as mean \pm s.e.m. ${ }^{*} p<0.05,{ }^{* *} p<0.01,{ }^{* * *} p<0.001$.

the animals were approved by the Institutional Animal Care and Use Committees of both Zhejiang University (No. 14843) and Institute of Zoology, Chinese Academy of Sciences (IOZ 2015) and followed the NIH "Guide for the Care and Use of Laboratory Animals."

\section{Calcium Imaging VNO Slice Preparation}

Animals were decapitated following anesthesia, and the mandible bone was cut off with a pair of scissors to remove the lower jaw. The ridged upper palate tissue was peeled off to expose the nasal cavity. The anterior and posterior ends of the nasal septum were cut to extract the VNO-containing portion, which was immediately transferred to the ice-cold oxygenated mouse artificial cerebro-spinal fluid $\left(95 \% \mathrm{O}_{2} / 5 \% \mathrm{CO}_{2} ; \mathrm{mACSF}\right.$ containing $125 \mathrm{mM} \mathrm{NaCl}, 2.5 \mathrm{mM} \mathrm{KCl}, 1 \mathrm{mM} \mathrm{MgCl} 2,1.25 \mathrm{mM}$ $\mathrm{NaH}_{2} \mathrm{PO}_{4}, 25 \mathrm{mM} \mathrm{NaHCO}_{3}, 2 \mathrm{mM} \mathrm{CaCl}, 10 \mathrm{mM}$ D-Glucose, $\mathrm{pH}$ 7.4) (Brechbühl et al., 2011; Ma et al., 2011). The cartilaginous capsule of the VNO was then removed to gain access to the luminal surface of the sensory epithelium. The dissected VNO 

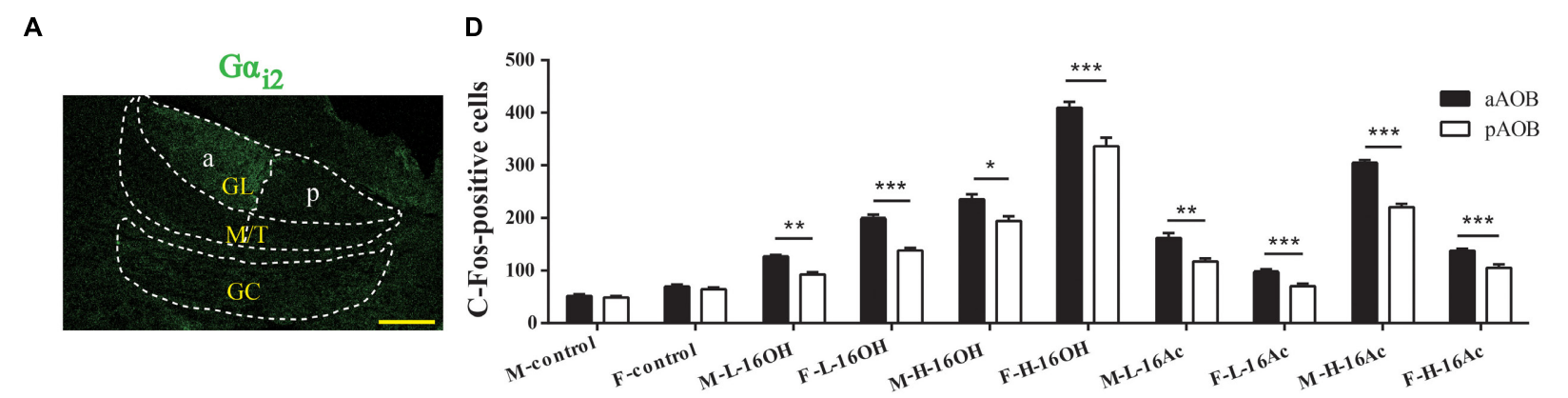

B
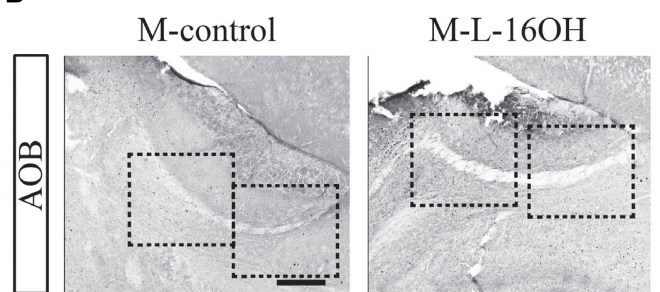

M-H-16OH
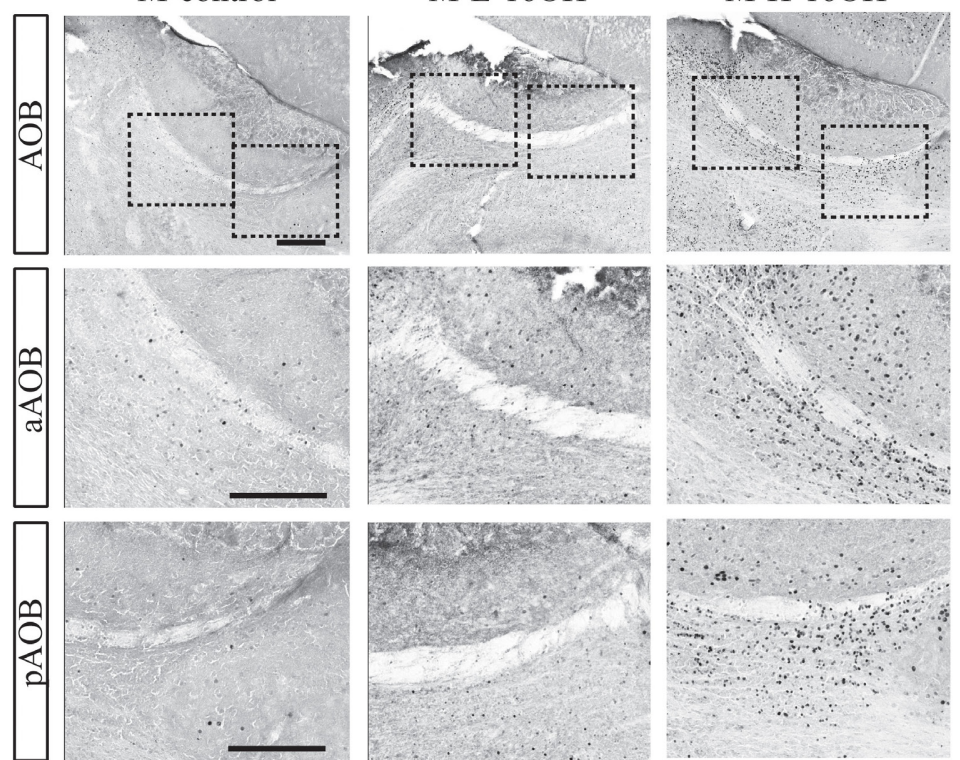

c

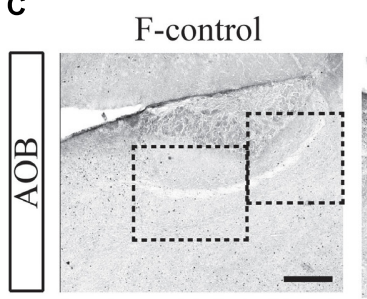

F-L-16OH
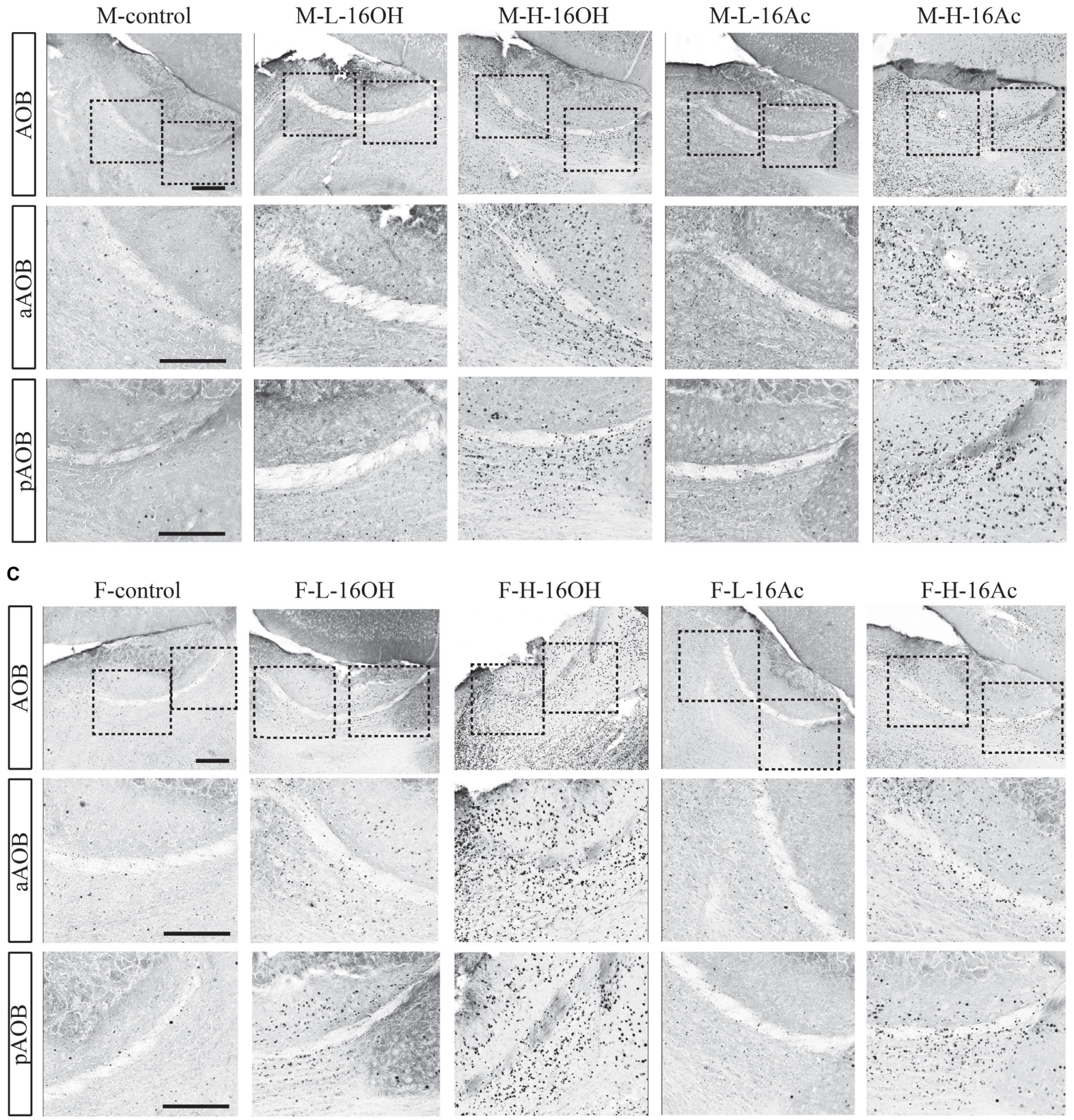

FIGURE 6 | Continued 


\begin{abstract}
FIGURE 6 | c-Fos+ neurons are found in mouse $\mathrm{aAOB}$ and $\mathrm{pAOB}$ after exposure to $16 \mathrm{OH}$ and $16 \mathrm{Ac}$. (A) Ga $\mathrm{i}_{2}$ immunostaining was used to identify the anterior and posterior halves of the $\mathrm{AOB}(\mathrm{AAOB}$ and $\mathrm{PAOB})$; dotted lines denoted the mitral and tufted cell layer (M/T) and granule cell layer (GC). (B) C-Fos-immunostaining images of male AOB sections stimulated by L-16OH (M-L-16OH), H-16OH (M-H-16OH), L-16Ac (M-L-16Ac), H-16Ac (M-H-16Ac) as well as mineral oil containing $0.01 \%$ DCM (M-control): Top row, the entire AOB; Middle and Bottom rows, regions of the $\mathrm{AAOB}$ and $\mathrm{pAOB}$ at a higher magnification, respectively.

(C) C-Fos-immunostaining images of the female AOB sections stimulated by L-16OH (F-L-16OH), H-16OH (F-H-16OH), L-16Ac (F-L-16Ac), H-16Ac (F-H-16Ac) as well as $0.01 \%$ DCM-containing mineral oil (F-control): Top row, the entire AOB; Middle and Bottom rows, aAOB and pAOB regions at a higher magnification, respectively. Scale bar, $200 \mu \mathrm{m}$. (D) Comparative analysis of the numbers of c-Fos+ neurons in the aAOB versus pAOB in response to both low and high $160 \mathrm{H}$ and $16 \mathrm{Ac}$ indicated that $\mathrm{AAOB}$ displayed significantly more c-Fos+ neurons than pAOB in responses to any one of these four stimuli (aAOB vs. pAOB: M-L-16OH, $t=6.680, p=0.001 ; \mathrm{M}-\mathrm{H}-16 \mathrm{OH}, t=5.566, p=0.003 ; \mathrm{F}-\mathrm{L}-16 \mathrm{OH}, t=9.868, p=0.000 ; \mathrm{F}-\mathrm{H}-16 \mathrm{OH}, t=9.399, p=0.000 ; \mathrm{M}-\mathrm{L}-16 \mathrm{Ac}, t=6.526, p=0.001$; $\mathrm{M}-\mathrm{H}-16 \mathrm{Ac}, t=10.043, p=0.000 ; \mathrm{F}-\mathrm{L}-16 \mathrm{Ac}, t=14.029, p=0.000 ; \mathrm{F}-\mathrm{H}-16 \mathrm{Ac}, t=7.243, p=0.000) . \mathrm{N}=6$ for each group. All values are expressed as mean \pm s.e.m. ${ }^{*} p<0.05,{ }^{* *} p<0.01,{ }^{* * *} p<0.001$.
\end{abstract}

was embedded in $3 \%$ low-melting agar and sliced coronally into $200 \mu \mathrm{m}$-thick sections with a vibratome at a speed of $0.5 \mathrm{~mm} / \mathrm{s}$ and amplitude of $0.7 \mathrm{~mm}$ (Leinders-Zufall et al., 2000).

\section{Calcium Imaging}

A VNO tissue slice was loaded with $10 \mu \mathrm{M}$ calcium-sensitive dye Fura-2-AM (F1201, Life Technology, United States) for 30$60 \mathrm{~min}$. Calcium imaging was performed on a Nikon microscope equipped with $20 \times, 40 \times$ water immersion objectives to monitor the changes in intracellular $\mathrm{Ca}^{2+}$ concentrations over time. Cells were illuminated sequentially at $340 / 380 \mathrm{~nm}$ with a polychromator instrument and emission at $510 \mathrm{~nm}$ was recorded at a rate of $5 \mathrm{~Hz}$. Changes in the intracellular emission ratio at 340 and $380 \mathrm{~nm}$, i.e., ratio $=\mathrm{F} 340 / \mathrm{F} 380 \mathrm{~nm}$, were monitored with Ratio Imaging software. Pheromones were delivered at a flow rate of $1 \mathrm{ml} / \mathrm{min}$ using a peristaltic pump. Near the end of each imaging session, $50 \mathrm{mM} \mathrm{KCl}$ in mACSF was applied to the $\mathrm{VNO}$ slice to check the viability and responsiveness of the cells and only the responsive VSNs were included in the post hoc data analyses. The interstimulus intervals were $4 \mathrm{~min}$ or longer to allow the recovery of the VSNs. Solutions of $16 \mathrm{OH}$ and 16Ac were prepared as stock solutions of $1 \mathrm{M}$ by being dissolved in dimethyl sulfoxide (DMSO) and then diluted in mACSF to two concentrations used in this study: low $(10 \mathrm{nM})$ and high $(100 \mu \mathrm{M})$. Thus, these four solutions: $10 \mathrm{nM} \mathrm{16OH}, 10 \mathrm{nM} \mathrm{16Ac}$, $100 \mu \mathrm{M} 16 \mathrm{OH}$, and $100 \mu \mathrm{M} 16 \mathrm{Ac}$ were designated as L-16OH, L$16 \mathrm{Ac}, \mathrm{H}-16 \mathrm{OH}$, and $\mathrm{H}-16 \mathrm{Ac}$, respectively (Leinders-Zufall et al., 2000; Isogai et al., 2011).

\section{Immunohistochemistry Pheromone Treatment}

To stimulate mice, $16 \mathrm{OH}$ and $16 \mathrm{Ac}$ stock solutions of $1 \mathrm{M}$ were prepared in dichloromethane (DCM) and diluted to $100 \mu \mathrm{M}$ in double distilled water for VNO experiment, or diluted to two concentrations: $10 \mathrm{nM}$ and $100 \mu \mathrm{M}$ in mineral oil for $\mathrm{AOB}$ and brain experiment; thus, the concentration of residual DCM in the pheromone solutions was $0.01 \%$ or less. Forty microliters of the pheromones or whole urine (positive control) or $0.01 \%$ DCM in double distilled water (negative control) for VNO staining, and pheromones or $0.01 \%$ DCM in mineral oil (negative control) for $\mathrm{AOB}$ and brain staining were added onto a piece of filter paper placed in a mould in the bedding of the subjects that had been previously housed individually for 2 days in a clean room. The treatment lasted for $45 \mathrm{~min}$ for the VNO experiments or $90 \mathrm{~min}$ for the $\mathrm{AOB}$ and brain experiments. Based on sex and treatment, the animals were divided into eight groups: male mice treated with urine (Male-urine), 0.01\% DCM-containing double distilled water (Male- $\mathrm{ddH}_{2} \mathrm{O}$ ), $16 \mathrm{OH}$ (Male-16OH), and $16 \mathrm{Ac}$ (Male-16Ac); and female mice treated with urine (Femaleurine), $0.01 \%$ DCM-containing double distilled water (Female$\mathrm{dd}_{2} \mathrm{O}$ ), $16 \mathrm{OH}$ (Female-16OH), and 16Ac (Female-16Ac) for the VNO experiments. And for the AOB and brain experiments, the animals were divided into 10 groups: male mice treated with 0.01\% DCM-containing mineral oil (designated as M-control), L-16OH (M-L-16OH), L-16Ac (M-L-16Ac), H-16OH (M-H$16 \mathrm{OH})$, or $\mathrm{H}-16 \mathrm{Ac}(\mathrm{M}-\mathrm{H}-16 \mathrm{Ac})$; and female mice treated with 0.01\% DCM-containing mineral oil (F-control), L-16OH (FL-16OH), L-16Ac (F-L-16Ac), H-16OH (F-H-16OH), or H$16 \mathrm{Ac}$ (F-H-16Ac).

\section{Tissue Preparation}

After pheromone treatment, the mice were anesthetized with sodium pentobarbital $(40 \mathrm{mg} / \mathrm{kg})$ and transcardially perfused with PBS followed by $4 \%$ paraformaldehyde (PFA) in PBS. Then, the VNO, OB, and brain were dissected out, postfixed overnight, and cryoprotected in 30\% sucrose solution in PBS overnight. Coronal sections of the VNO (12 $\mu \mathrm{m}$ thick) and brain (40 $\mu \mathrm{m}$ thick) and sagittal sections of the $\mathrm{OB}$ (30 $\mu \mathrm{m}$ thick) were sliced and collected. The brain sections that contained the nuclei potentially involved in the processing of $16 \mathrm{OH}$ and 16Ac signals, including the BNST, MPA, anterior subdivision of the MeA, ventromedial hypothalamic nucleus $(\mathrm{VmH})$, posteromedial cortical amygdaloid nucleus (PMCo), were collected (Supplementary Figure 1; Paxinos and Franklin, 2004). The intervals between sections from the brain and OB were 40 and $30 \mu \mathrm{m}$ apart, respectively.

\section{Double Immunostaining With Anti-pS6 and Anti-G $\alpha_{0}$ Antibodies on the VNO Sections (Jiang et al., 2015)}

The VNO sections were washed with PBS to remove the embedding medium and blocked by incubating with the blocking buffer (10\% normal goat serum, $2 \%$ bovine serum albumin in $0.5 \%$ Triton X-100/PBS solution) for $1 \mathrm{~h}$. The anti-G $\alpha_{o}$ primary antibody (551, Medical and Biological Laboratories, Japan) was diluted at 1:2000 in the dilution buffer ( $2 \%$ normal goat serum, $2 \% \mathrm{BSA}$ in $0.5 \%$ Triton X-100/PBS) and applied to the sections for $16 \mathrm{~h}$, followed by the incubation with AF568-conjugated goat-anti-rabbit secondary antibody diluted at 1:500 (ab175471, Abcam, United Kingdom) for $1 \mathrm{~h}$. The anti-pS6 antibody (4856S, Cell Signaling Technology, Japan) was conjugated with AF488 


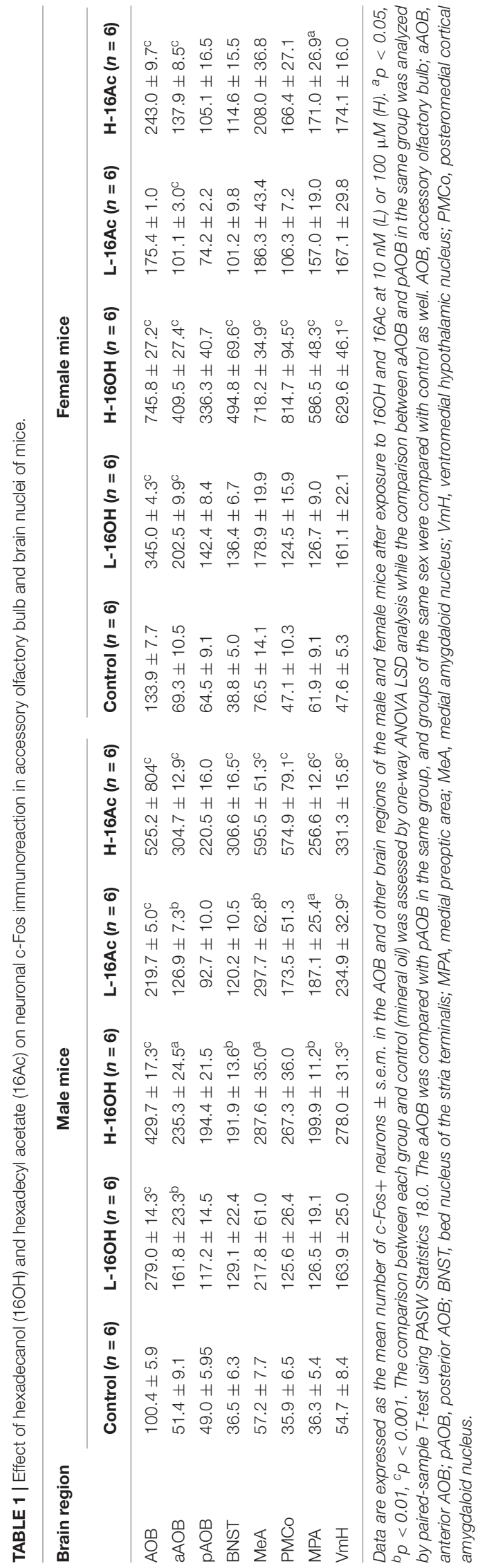

using Zenon Rabbit lgG Labeling Kit (Z25302, Molecular Probes, United States) and applied to the sections for 1-2 h. Finally, the sections were washed with $1 \times$ PBS and covered with the mounting medium containing DAPI.

\section{c-Fos Immunohistochemistry}

Tissue sections were washed with PBS and incubated in 3\% hydrogen peroxide in PBS for 30 min to eliminate background signals. After incubation with the blocking buffer for $1 \mathrm{~h}$, tissue sections were incubated with the anti-c-Fos primary antibody (ab190289, Abcam, United Kingdom) diluted at 1:2000 for $16 \mathrm{~h}$ at $4^{\circ} \mathrm{C}$, and then with the goat-anti-rabbit secondary antibody (BA1000 , Vector Laboratories, United States) diluted at 1:300 for $1 \mathrm{~h}$, and finally with the avidin-biotin-peroxidase complex solution (PK-6100, ABC Kit, Vector Laboratories, United States) for $40 \mathrm{~min}$. The sections were reacted with DAB Substrate Kit (SK4100, Vector Laboratories, United States) for 2-3 min (Halem et al., 1999; Honda et al., 2008; Fabianová et al., 2014), and imaged with a Leica panoramic tissue cell scanning microscope.

\section{Double Immunostaining With Anti-c-Fos and Anti-G $\alpha_{\mathrm{i} 2}$ Antibodies}

Following the c-Fos immunohistochemistry described above, the sections were blocked again in the blocking buffer, and then incubated with the anti-G $\alpha_{\mathrm{i} 2}$ primary antibody (sc-13534, Santa Cruz, United States) at 1:500 dilution for $16 \mathrm{~h}$ at $4^{\circ} \mathrm{C}$, followed by incubation with the AF488-conjugated goatanti-mouse secondary antibody (A32723, Life Technologies, United States) at 1:2000 dilution for $1 \mathrm{~h}$. Finally, the sections were washed with $1 \times$ PBS and covered with the mounting medium containing DAPI.

\section{Quantification of c-Fos+ Cells}

The numbers of the c-Fos expressing cells in the different regions of the AOB and brain were counted using the Image J software. The experimenter was blind to the treatments. And the thresholds of c-Fos signal intensity and the cell size were set to cover all identifiable c-Fos + neurons in the image. The numbers of c-Fos+ cells in the glomerular layer (GL), mitral/tufted cell (MTC) layer, and the granule cell (GC) layer were summed up as the total numbers of the activated cells in the anterior and posterior $\mathrm{AOB}$ halves. For the brain regions, c-Fos+ cells from five sections located at the same distance of bregma were counted for a particular brain region (Supplementary Figure 2) and the mean value was calculated as the final number of activated neurons from that region of an animal (Paxinos and Franklin, 2004).

\section{Statistical Analysis}

Calcium imaging data were expressed as the mean \pm s.e.m. The data distribution and homogeneity of variances were checked. The differences between groups with different sexes, pheromones, and concentrations were assessed by two-way ANOVA with sex as between-group factor and treatment as within-group factor. If significant interaction was found, a post hoc analysis with Bonferroni's multiple comparison tests was performed to identify significant differences with PASW Statistics 18.0 software. c-Fos immunohistochemistry data 


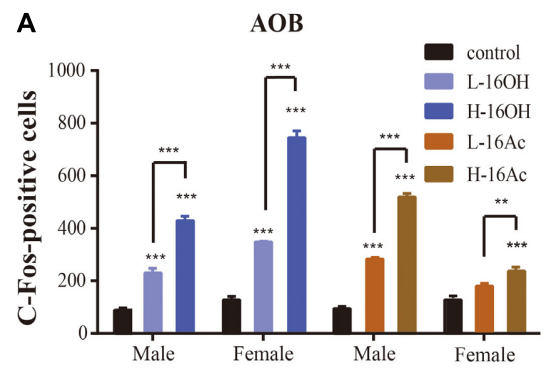

D

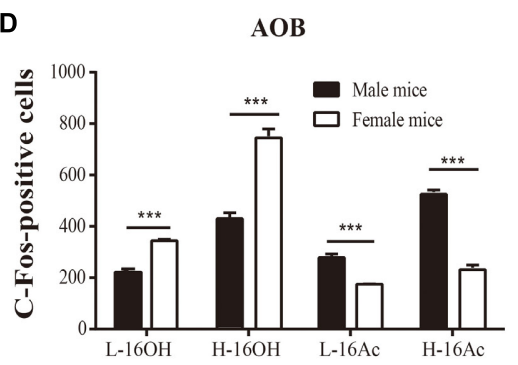

G

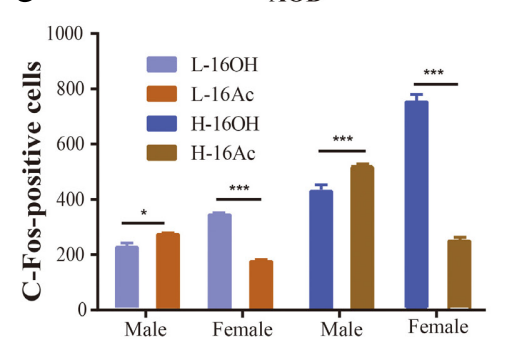

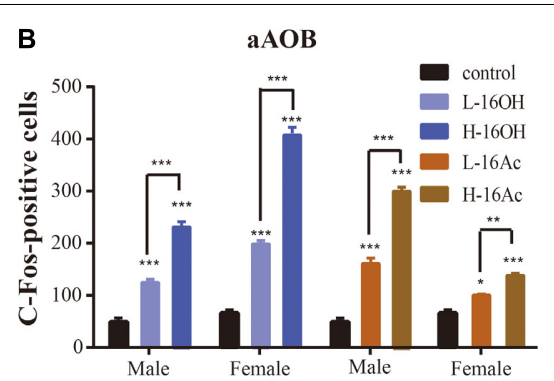

E

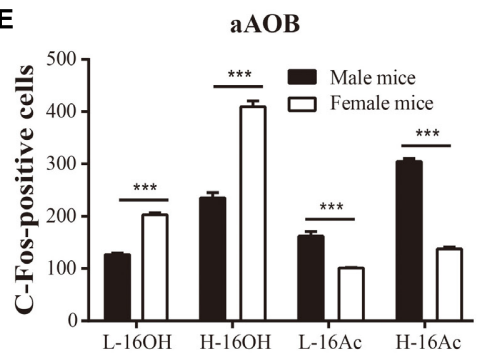

H

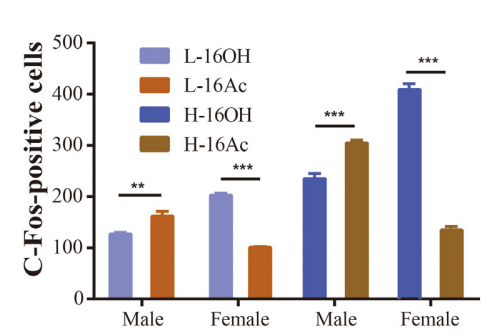

C

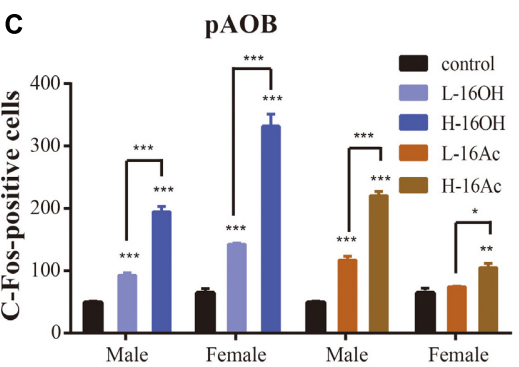

F

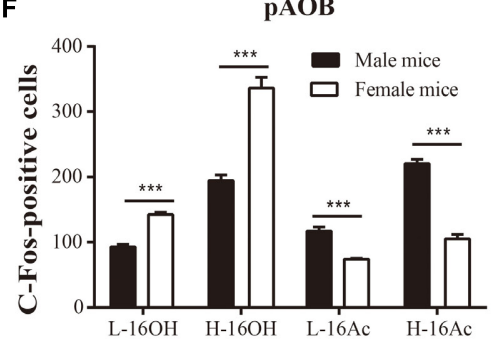

I

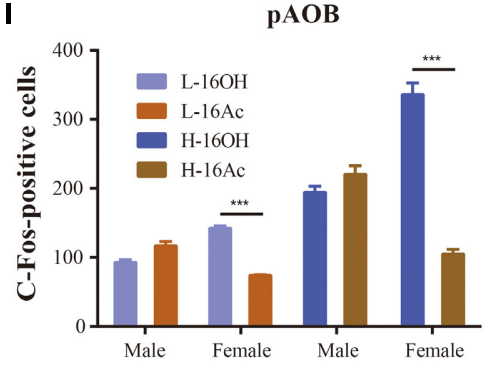

FIGURE 7 | Quantitative analysis of C-Fos+ AOB neurons of the male and female mice after exposure to $160 \mathrm{H}$ and $16 \mathrm{Ac}$. (A) Significantly more activated neurons were found in both male and female $\mathrm{aAOB}$ and $\mathrm{pAOB}$ following stimulation by all these four stimuli: low or high $16 \mathrm{OH}$ or $16 \mathrm{Ac}$ in comparison with the control samples except the L-16Ac in female mice (M-L-16OH vs. M-control, $t=6.780, p=0.000 ; \mathrm{M}-\mathrm{H}-160 \mathrm{H}$ vs. $\mathrm{M}-\mathrm{control}, t=18.717, p=0.000 ; \mathrm{M}-\mathrm{L}-16 \mathrm{Ac}$ vs. $\mathrm{M}$-control, $t=10.148, p=0.000 ; \mathrm{M}-\mathrm{H}-16 \mathrm{Ac}$ vs. M-control, $t=24.142, p=0.000 ; \mathrm{F}-\mathrm{L}-16 \mathrm{OH}$ vs. F-control, $t=11.996, p=0.000 ; \mathrm{F}-\mathrm{H}$-16OH vs. F-control, $t=34.776, p=0.000 ; \mathrm{F}-\mathrm{L}-16 \mathrm{Ac}$ vs. F-control, $t=2.364, p=0.220 ; \mathrm{F}-\mathrm{H}-16 \mathrm{Ac}$ vs. F-control, $t=6.200, p=0.000) . \mathrm{H}-16 \mathrm{OH}$ or $\mathrm{H}-16 \mathrm{Ac}$ evoked more c-Fos+ AOB neurons than the corresponding $\mathrm{L}-16 \mathrm{OH}$ and $\mathrm{L}-16 \mathrm{Ac}$, respectively, in the mice of the same sex $(\mathrm{M}-\mathrm{H}-16 \mathrm{OH}$ vs. $\mathrm{M}-\mathrm{L}-16 \mathrm{OH}, t=11.937, p=0.000 ; \mathrm{M}-\mathrm{H}-16 \mathrm{Ac}$ vs. $\mathrm{M}-\mathrm{L}-16 \mathrm{Ac}, t=13.994, p=0.000 ; \mathrm{F}-\mathrm{H}-160 \mathrm{H}$ vs. F-L-16OH, $t=22.780, p=0.000 ; \mathrm{F}-\mathrm{H}-16 \mathrm{Ac}$ vs. F-L-16Ac, $t=3.836, p=0.004$ ). (B) Comparative analysis of the c-Fos+ cells in the $\mathrm{AAOB}$ of the same sex exposed to the same pheromone at either the low or high concentration. Significantly more activated neurons were found in both male and female $\mathrm{AAOB}$ following stimulation by all these four stimuli: low or high $16 \mathrm{OH}$ or $16 \mathrm{Ac}$ in comparison with the control samples whereas $\mathrm{H}-16 \mathrm{OH}$ or $\mathrm{H}-16 \mathrm{Ac}$ evoked more c-Fos+ aAOB neurons than the corresponding L-16OH and L-16Ac, respectively, in the mice of the same sex (M-L-16OH vs. M-control, $t=8.302, p=0.000 ; \mathrm{M}-\mathrm{H}-16 \mathrm{OH}$ vs. M-control, $t=20.212, p=0.000 ; \mathrm{M}-\mathrm{H}-16 \mathrm{OH}$ vs. M-L-16OH, $t=11.910, p=0.000 ; \mathrm{M}-\mathrm{L}-16 \mathrm{Ac}$ vs. $\mathrm{M}-\mathrm{control}, t=12.126$, $p=0.000 ; \mathrm{M}-\mathrm{H}-16 \mathrm{Ac}$ vs. M-control, $t=27.836, p=0.000 ; \mathrm{M}-\mathrm{H}-16 \mathrm{Ac}$ vs. $\mathrm{M}-\mathrm{L}-16 \mathrm{Ac}, t=10.078, p=0.000 ; \mathrm{F}-\mathrm{L}-160 \mathrm{H}$ vs. F-control, $t=14.637, p=0.000 ;$ $\mathrm{F}-\mathrm{H}-16 \mathrm{OH}$ vs. F-control, $t=37.370, p=0.000 ; \mathrm{F}-\mathrm{H}-16 \mathrm{OH}$ vs. F-L-16OH, $t=22.733, p=0.000 ; \mathrm{F}-\mathrm{L}-16 \mathrm{Ac}$ vs. F-control, $t=3.499, p=0.010 ; \mathrm{F}-\mathrm{H}-16 \mathrm{Ac}$ vs. F-control, $t=7.529, p=0.000 ; \mathrm{F}-\mathrm{H}-16 \mathrm{Ac}$ vs. F-L-16Ac, $t=4.030, p=0.002)$. (C) Comparative analysis of the c-Fos+ cells in the pAOB of the same sex mice exposed to the same pheromone at the either low or high concentration $(\mathrm{M}-\mathrm{L}-16 \mathrm{OH}$ vs. $\mathrm{M}$-control, $t=4.266, p=0.000 ; \mathrm{M}-\mathrm{H}-16 \mathrm{OH}$ vs. $\mathrm{M}-\mathrm{control}, t=14.180$, $p=0.000 ; \mathrm{M}-\mathrm{H}-16 \mathrm{OH}$ vs. $\mathrm{M}-\mathrm{L}-16 \mathrm{OH}, t=9.915, p=0.000 ; \mathrm{M}-\mathrm{L}-16 \mathrm{Ac}$ vs. M-control, $t=6.651, p=0.000 ; \mathrm{M}-\mathrm{H}-16 \mathrm{Ac}$ vs. $\mathrm{M}-\mathrm{control}, t=16.729, p=0.000 ;$ $\mathrm{M}-\mathrm{H}-16 \mathrm{Ac}$ vs. M-L-16Ac, $t=10.078, p=0.000 ; \mathrm{F}-\mathrm{L}-16 \mathrm{OH}$ vs. F-control, $t=7.596, p=0.000 ; \mathrm{F}-\mathrm{H}-16 \mathrm{OH}$ vs. F-control, $t=26.515, p=0.000 ; \mathrm{F}-\mathrm{H}-160 \mathrm{H}$ vs. $\mathrm{F}-\mathrm{L}-16 \mathrm{OH}, t=18.919, p=0.000 ; \mathrm{F}-\mathrm{L}-16 \mathrm{Ac}$ vs. F-control, $t=0.950, p=1.000 ; \mathrm{F}-\mathrm{H}-16 \mathrm{Ac}$ vs. F-control, $t=3.639, p=0.002 ; \mathrm{F}-\mathrm{H}-16 \mathrm{Ac}$ vs. F-L-16Ac, $t=3.007$, $p=0.041)$. (D) Comparative analysis of c-Fos+ neurons in the AOB of males versus females stimulated by $16 \mathrm{OH}$ or $16 \mathrm{Ac}$ at the low or high concentration (F-L-16OH vs. M-L-16OH, $t=7.119, p=0.000 ; \mathrm{F}-\mathrm{H}-16 \mathrm{OH}$ vs. $\mathrm{M}-\mathrm{H}-16 \mathrm{OH}, t=17.963, p=0.000 ; \mathrm{M}-\mathrm{L}-16 \mathrm{Ac}$ vs. F-L-16Ac, $t=5.881, p=0.000 ; \mathrm{M}-\mathrm{H}-16 \mathrm{Ac}$ vs. $\mathrm{F}-\mathrm{H}-16 \mathrm{Ac}, t=16.039, p=0.000)$. (E,F) Comparative analysis of $\mathrm{c}-\mathrm{Fos}+$ neurons to $16 \mathrm{OH}$ and $16 \mathrm{Ac}$ between male and female aAOB and $\mathrm{pAOB}$, respectively. Female $\mathrm{AAOB}$ and $\mathrm{pAOB}$ responded more strongly to $\mathrm{L}$ - or $\mathrm{H}-16 \mathrm{OH}$ than male $\mathrm{AAOB}$ and $\mathrm{pAOB}$, respectively, whereas male aAOB and $\mathrm{pAOB}$ did more strongly to $\mathrm{L}$ - or $\mathrm{H}-16 \mathrm{Ac}$ than female aAOB and pAOB, respectively (aAOB: $\mathrm{F}-\mathrm{L}-16 \mathrm{OH}$ vs. $\mathrm{M}-\mathrm{L}-16 \mathrm{OH}, t=8.307, p=0.000 ; \mathrm{F}-\mathrm{H}-16 \mathrm{OH}$ vs. $\mathrm{M}-\mathrm{H}-16 \mathrm{OH}, t=19.130, p=0.000$; $\mathrm{M}-\mathrm{L}-16 \mathrm{Ac}$ vs. F-L-16Ac, $t=6.655, p=0.000 ; \mathrm{M}-\mathrm{H}-16 \mathrm{Ac}$ vs. F-H-16Ac, $t=18.335, p=0.000 ; \mathrm{pAOB}: \mathrm{F}-\mathrm{L}-16 \mathrm{OH}$ vs. $\mathrm{M}-\mathrm{L}-16 \mathrm{OH}, t=4.844, p=0.000 ; \mathrm{F}-\mathrm{H}-16 \mathrm{OH}$ vs. $\mathrm{M}-\mathrm{H}-16 \mathrm{OH}, t=13.849, p=0.000 ; \mathrm{M}-\mathrm{L}-16 \mathrm{Ac}$ vs. F-L-16Ac, $t=4.187, p=0.000 ; \mathrm{M}-\mathrm{H}-16 \mathrm{Ac}$ vs. F-H-16Ac, $t=11.258, p=0.000$ ). (G-I) Comparison of the efficacy of $16 \mathrm{OH}$ versus $16 \mathrm{Ac}$ on evoking the c-Fos response in the $\mathrm{AOB}$. $16 \mathrm{OH}$ seemed to be more effective on the female $\mathrm{AOB}$, aAOB, or pAOB than on the male counterparts while 16Ac was more effective on male AOB, aAOB, or pAOB than on the female counterparts $(A O B$ : $M-L-16 A c$ vs. $M-L-16 O H, t=3.368, p=0.015$; $\mathrm{M}-\mathrm{H}-16 \mathrm{Ac}$ vs. $\mathrm{M}-\mathrm{H}-16 \mathrm{OH}, t=5.426, p=0.000 ; \mathrm{F}-\mathrm{L}-16 \mathrm{OH}$ vs. F-L-16Ac, $t=9.632, p=0.000 ; \mathrm{F}-\mathrm{H}-16 \mathrm{OH}$ vs. F-H-16Ac, $t=28.576, p=0.000 ; a A O B: \mathrm{M}-\mathrm{L}-16 \mathrm{Ac}$ vs. $\mathrm{M}-\mathrm{L}-16 \mathrm{OH}, t=3.825, p=0.004 ; \mathrm{M}-\mathrm{H}-16 \mathrm{Ac}$ vs. $\mathrm{M}-\mathrm{H}-16 \mathrm{OH}, t=7.624, p=0.000 ; \mathrm{F}-\mathrm{L}-16 \mathrm{OH}$ vs. F-L-16Ac, $t=11.138, p=0.000 ; \mathrm{F}-\mathrm{H}-16 \mathrm{OH}$ vs. F-H-16Ac, $t=29.841, p=0.000 ;$ pAOB: M-L-16Ac vs. M-L-16OH, $t=2.386, p=0.209 ; \mathrm{M}-\mathrm{H}-16 \mathrm{Ac}$ vs. $\mathrm{M}-\mathrm{H}-16 \mathrm{OH}, t=2.548, p=0.139 ; \mathrm{F}-\mathrm{L}-16 \mathrm{OH}$ vs. F-L-16Ac, $t=6.646$, $p=0.000 ; \mathrm{F}-\mathrm{H}-16 \mathrm{OH}$ vs. $\mathrm{F}-\mathrm{H}-16 \mathrm{Ac}, t=22.559, p=0.000) . N=6$ for each group. All values are expressed as mean $\pm \mathrm{s} . \mathrm{e} . \mathrm{m} .{ }^{*} p<0.05,{ }^{*} p<<0.01,{ }^{* * *} p<0.001$. 


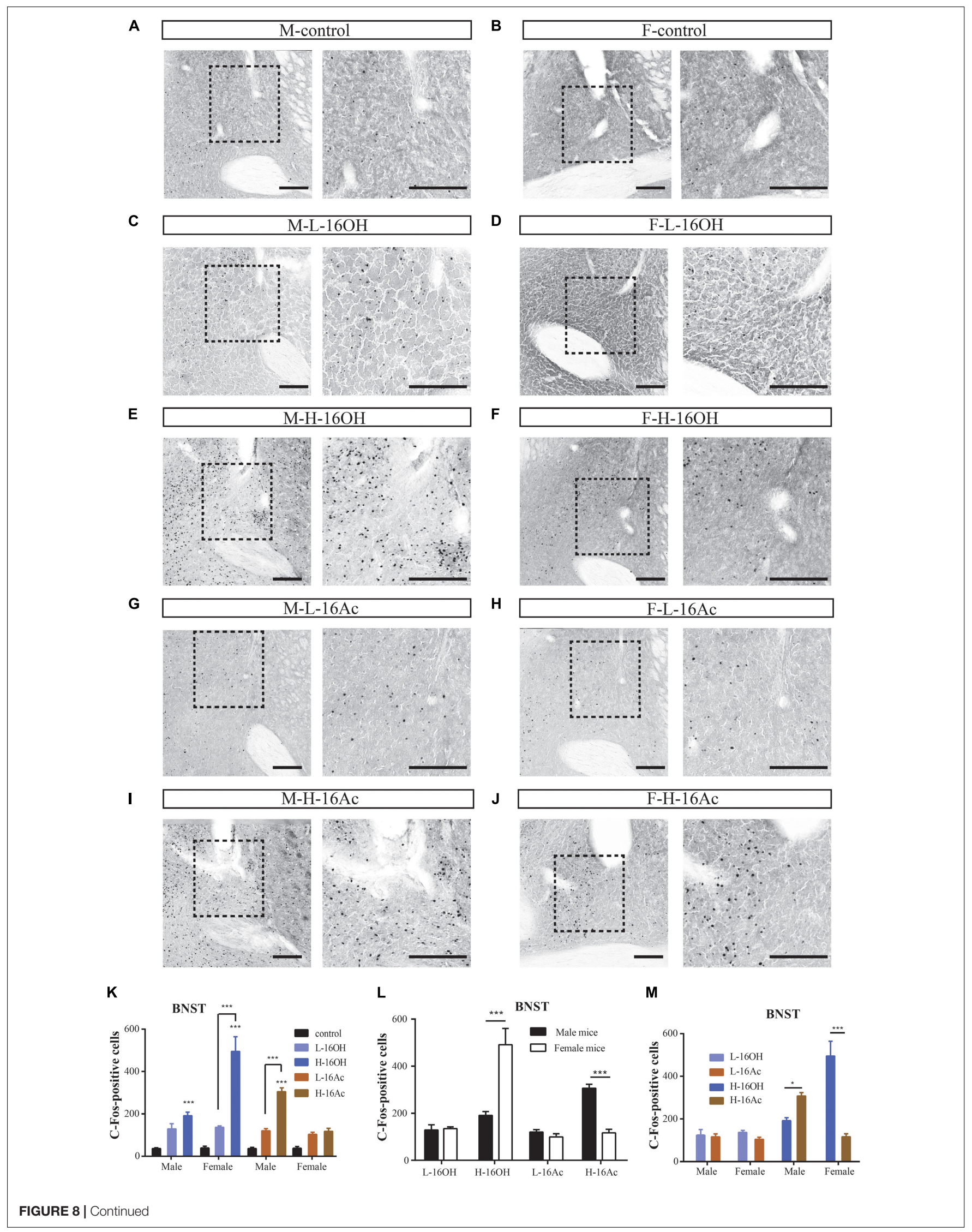


FIGURE 8 | Representative images and quantification of c-Fos+ neurons in the bed nucleus of the stria terminalis (BNST) induced by $160 \mathrm{H}$ and 16 Ac. (A-J) Representative images and their insets of C-Fos+ cells in the BNST of male or female mice after exposure to $0.01 \%$ DCM-containing mineral oil (control), L-16OH, $\mathrm{H}-16 \mathrm{OH}, \mathrm{L}-16 \mathrm{Ac}$, and $\mathrm{H}-16 \mathrm{Ac}$, respectively. Scale bar, $200 \mu \mathrm{m}$. (K) All treatments of $\mathrm{H}-16 \mathrm{OH}$ and $\mathrm{H}-16 \mathrm{AC}$ except $\mathrm{H}-16 \mathrm{Ac}$ on the female BNST evoked significantly stronger c-Fos immunoreactivity in the male and female BNST than the control (M-L-16OH vs. M-control, $t=2.598, p=0.123 ; \mathrm{M}-\mathrm{H}-16 \mathrm{OH}$ vs. $\mathrm{M}-\mathrm{control}, t=4.358$, $p=0.000 ; \mathrm{M}-\mathrm{L}-16 \mathrm{Ac}$ vs. M-control, $t=2.348, p=0.228 ; \mathrm{M}-\mathrm{H}-16 \mathrm{Ac}$ vs. M-control, $t=7.577, p=0.000 ; \mathrm{F}-\mathrm{L}-16 \mathrm{OH}$ vs. F-control, $t=2.737, p=0.086 ; \mathrm{F}-\mathrm{H}-16 \mathrm{OH}$ vs. F-control, $t=12.793, p=0.000 ; \mathrm{F}-\mathrm{L}-16 \mathrm{Ac}$ vs. F-control, $t=1.752, p=0.860 ; \mathrm{F}-\mathrm{H}$-16Ac vs. F-control, $t=2.172, p=0.384)$. And $\mathrm{H}$-16OH evoked significantly stronger c-Fos immunoreactivity than $\mathrm{L}-16 \mathrm{OH}$ in the female but not male mice whereas $\mathrm{H}-16 \mathrm{Ac}$ did so than $\mathrm{L}-16 \mathrm{Ac}$ in the opposite sex (F-H-16OH vs. F- $\mathrm{L}-16 \mathrm{OH}$, $t=10.056, p=0.000 ; \mathrm{M}-\mathrm{H}-16 \mathrm{OH}$ vs. $\mathrm{M}-\mathrm{L}-16 \mathrm{OH}, t=1.760, p=0.845 ; \mathrm{M}-\mathrm{H}-16 \mathrm{Ac}$ vs. $\mathrm{M}-\mathrm{L}-16 \mathrm{Ac}, t=5.229, p=0.000 ; \mathrm{F}-\mathrm{H}-16 \mathrm{Ac}$ vs. F-L-16Ac, $t=0.375$,

$p=1.000$ ). (L) Comparison between sexes indicates that the female BNST responded more strongly to $\mathrm{H}-16 \mathrm{OH}$ than the male BNST whereas the male BNST did so to $\mathrm{H}-16 \mathrm{Ac}$ than the female BNST ( $\mathrm{F}-\mathrm{H}-16 \mathrm{OH}$ vs. $\mathrm{M}-\mathrm{H}-160 \mathrm{H}, t=8.499, p=0.000 ; \mathrm{M}-\mathrm{H}-16 \mathrm{Ac}$ vs. F-H-16Ac, $t=5.387, p=0.000$ ). (M) Comparison between the two pheromones indicates that $\mathrm{H}-16 \mathrm{OH}$ was more effective than $\mathrm{H}-16 \mathrm{Ac}$ on the female BNST whereas $\mathrm{H}$-16Ac was more so than $\mathrm{H}$-16OH on the male BNST

$(\mathrm{F}-\mathrm{H}-16 \mathrm{OH}$ vs. F-H-16Ac, $t=10.667, p=0.000 ; \mathrm{M}-\mathrm{H}-16 \mathrm{Ac}$ vs. $\mathrm{M}-\mathrm{H}-16 \mathrm{OH}, t=3.219, p=0.023) . \mathrm{N}=6$ for each group. All values are expressed as mean \pm s.e.m. ${ }^{*} p<0.05,{ }^{* * *} p<0.001$.

were also expressed as the mean \pm s.e.m, and checked for distribution and homogeneity of variances. Two-way ANOVA was performed with both sex and treatment as between-group factors. After the significant interaction was found, similar post hoc analyses with Bonferroni's multiple comparison tests were carried out as with the calcium imaging data using PASW Statistics 18.0 software.

\section{RESULTS}

\section{Hexadecanol and Hexadecyl Acetate Can Activate the Vomeronasal Sensory Neurons of Male and Female Mice}

To determine at the cellular level whether hexadecanol $(16 \mathrm{OH})$ and hexadecyl acetate (16Ac) can indeed function as pheromones on mice, we investigated VSN responses to these two compounds using calcium imaging on the vomeronasal sensory epithelium slices. The VSNs were loaded with the calcium-sensitive dye Fura 2-AM and stimulated sequentially with the two pheromones (Figures 1A,B). The results showed that increases in the intracellular calcium concentrations were observed in some VSNs in response to $100 \mu \mathrm{M} 16 \mathrm{OH}$ and $100 \mu \mathrm{M}$ 16Ac. Based on their responsiveness profiles, these VSNs could be classified into four types: those responsive to $16 \mathrm{OH}$ alone, to $16 \mathrm{Ac}$ alone, to both, or neither (Figures 1C,D).

From 5 male mice, out of 1175 VSNs examined, 14 (1.19\%), $11(0.93 \%)$, and $7(0.6 \%)$ of VSNs responded to L-16OH, L-16Ac, or both, respectively (Figure 2A) whereas out of 988 VSNs examined, 17 (1.7\%), 11 (1.1\%), and $8(0.81 \%)$ responded to $\mathrm{H}-16 \mathrm{OH}, \mathrm{H}-16 \mathrm{Ac}$, or both, respectively (Figure 2B). On the other hand, from 5 female mice, out of 1168 VSNs examined, 23 (1.97\%), 10 $(0.86 \%)$, and $6(0.51 \%)$ responded to L-16OH, L-16Ac, or both, respectively (Figure 3A) whereas out of 964 VSNs examined, 41 (4.25\%) responded to $\mathrm{H}-16 \mathrm{OH}, 17$ $(1.76 \%)$ to $\mathrm{H}-16 \mathrm{Ac}$, and $16(1.66 \%)$ to both, respectively (Figure 3B). Two-way ANOVA analysis with sex as a between-group factor and pheromone treatment as a within-group factor found that the effects of interaction $\left(F_{(5,90)}=3.3, p=0.0088\right)$, sex $\left(F_{(1,18)}=11.8, p=0.0029\right)$, and pheromone treatment $\left(F_{(5,90)}=10.56, p<0.0001\right)$ were all significant. A post hoc analysis with Bonferroni's correction showed that no statistically significant difference was found among the numbers of cells responsive to $\mathrm{L}-16 \mathrm{OH}$, L-16Ac, or both (Figure 2A), or among the numbers of cells responsive to $\mathrm{H}-16 \mathrm{OH}, \mathrm{H}-16 \mathrm{Ac}$, or both (Figure 2B), neither was found between the numbers of cells responsive to $\mathrm{L}$ - versus $\mathrm{H}-16 \mathrm{OH}$, or $\mathrm{L}$ - versus $\mathrm{H}-16 \mathrm{Ac}$ in the male mice (Figure 2C).

In the female mice, however, significantly more VSNs responded to $\mathrm{L}-16 \mathrm{OH}$ than to both, whereas no significant differences in the numbers of the VSNs responsive to L$16 \mathrm{OH}$ versus to $\mathrm{L}-16 \mathrm{Ac}$ or to $\mathrm{L}-16 \mathrm{Ac}$ versus to both $\mathrm{L}$ $16 \mathrm{OH}$ and L-16Ac were found (Figure 3A). When the high concentration was applied, significantly more VSNs responded to $\mathrm{H}-16 \mathrm{OH}$ than to $\mathrm{H}-16 \mathrm{Ac}$ or to both, whereas cells responsive to $\mathrm{H}-16 \mathrm{Ac}$ were not significantly more than those to both (Figure 3B). Further analysis showed that $\mathrm{H}-16 \mathrm{OH}$ activated more female VSNs than L-16OH, but the numbers of the cells responsive to $16 \mathrm{Ac}$ alone or to both were unaffected by their concentrations (Figure 3C).

Comparative analysis of the VSN responsiveness between sexes indicated that no significant differences were found between male and female VSNs in response to $\mathrm{L}-16 \mathrm{OH}$ alone, $\mathrm{L}$ - or $\mathrm{H}$ $16 \mathrm{Ac}$ alone, both $\mathrm{L}-16 \mathrm{OH}$ and L-16Ac, or both $\mathrm{H}-16 \mathrm{OH}$ and $\mathrm{H}-16 \mathrm{Ac}$ except that significantly more female VSNs than male VSNs responded to $\mathrm{H}-16 \mathrm{OH}$ (Figure 4).

\section{The Activated VSNs Are Mostly Located in the Apical Vomeronasal Sensory Epithelium}

To determine which type of the VSNs responsive to the two pheromones, we used an antibody to the phosphorylated small ribosomal protein 6 (pS6) to identify activated VSNs and another antibody to $\mathrm{G} \alpha \mathrm{o}$ to distinguish the apical layer from the basal layer of the vomeronasal sensory epithelium (Figures 5A,B; Jiang et al., 2015). The results show that significantly more pS6-expressing VSNs in both male and female mice were located in the apical VSE than in the basal VSE in response to $16 \mathrm{OH}$ and $16 \mathrm{Ac}$, which was similar to the pattern evoked by mouse urine, whereas the numbers of the activated neurons between the aVSE and bVSE of the control mice exposed to double distilled water $\left(\mathrm{ddH}_{2} \mathrm{O}\right)$ were not significantly different (Figures 5C,D). 
A

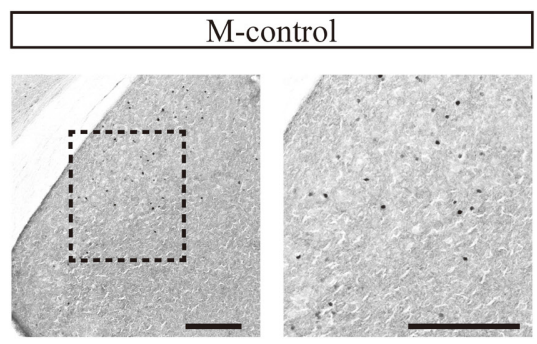

c
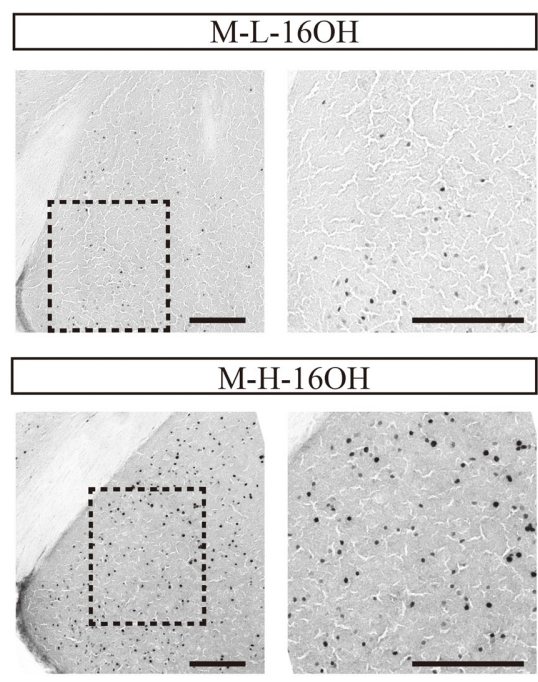

G

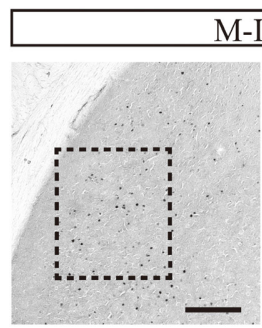

I

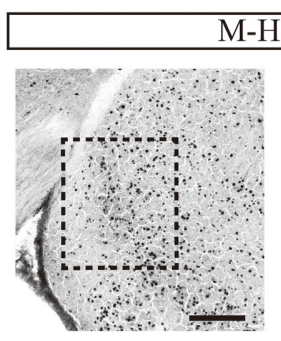

K
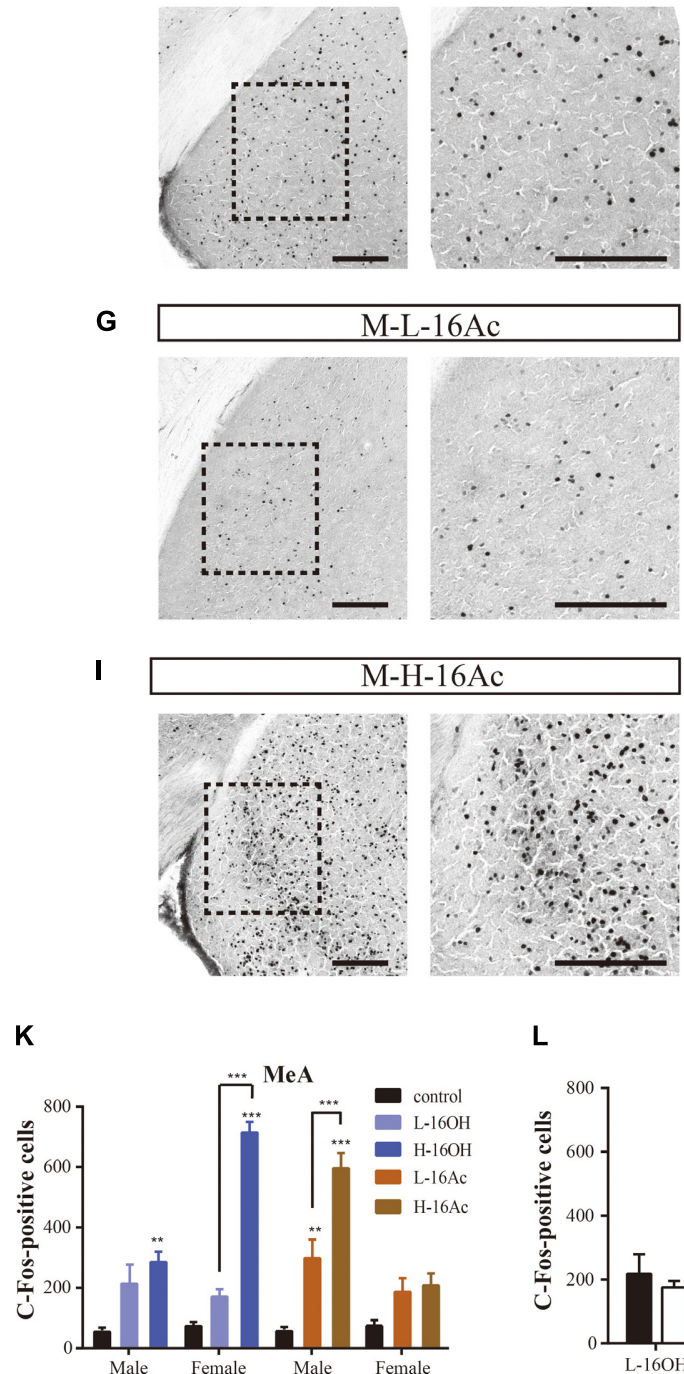

L
B

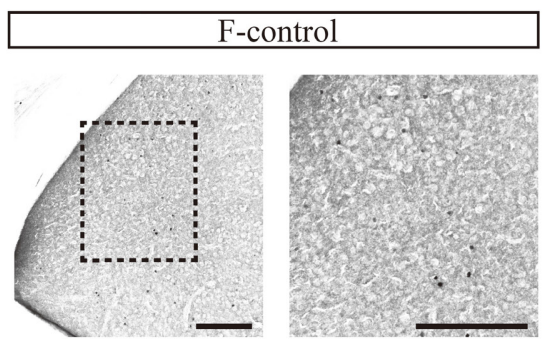

D
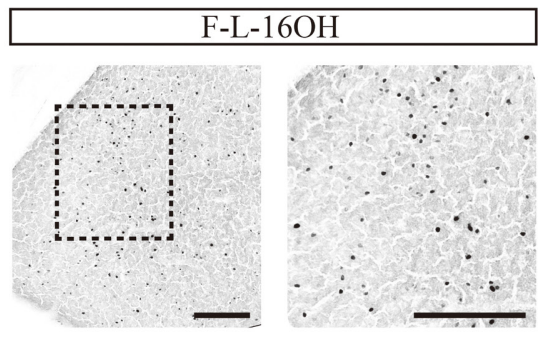

$\mathbf{F}$

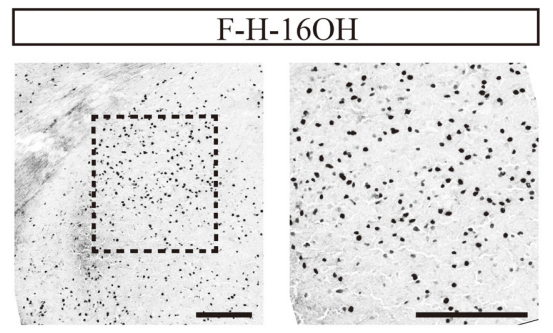

H

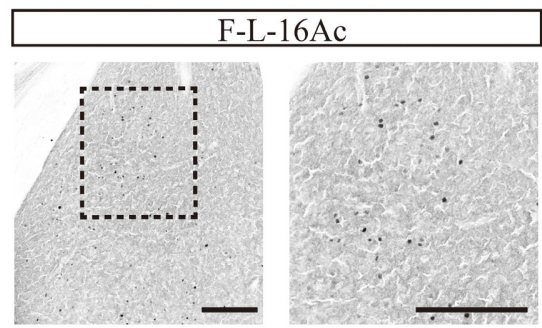

J
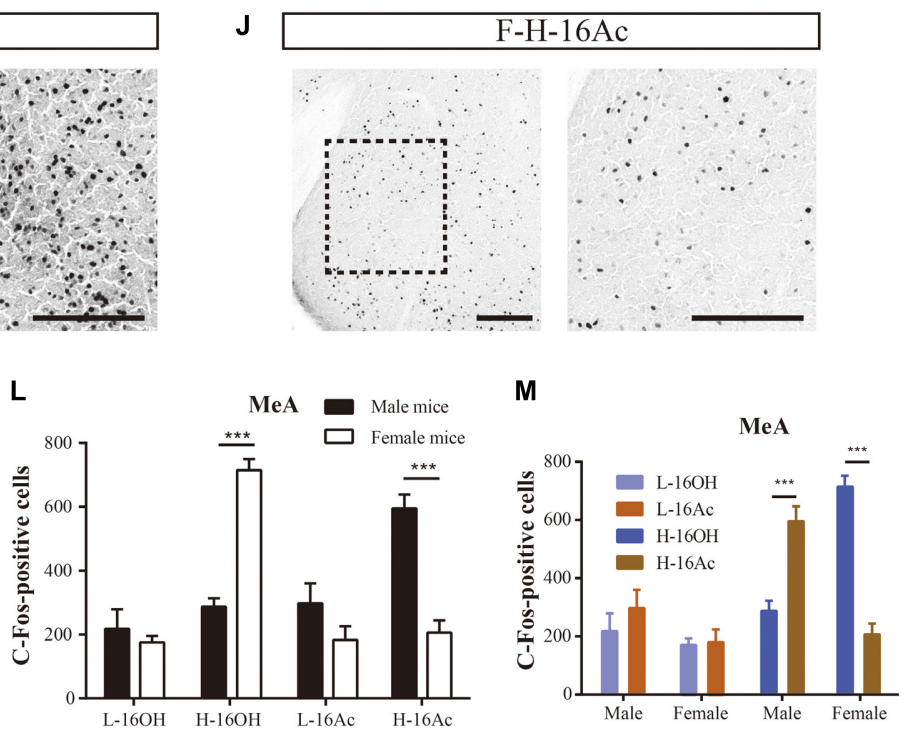

FIGURE 9 | Continued 


\begin{abstract}
FIGURE 9 | Representative images and quantification of c-Fos+ neurons in the anterior subdivision of the medial amygdaloid nucleus (MeA). (A-J) Representative images and their insets of C-Fos+ cells in the male and female MeA after exposure to $0.01 \% \mathrm{DCM}$-containing mineral oil (control), $\mathrm{L}$ - and $\mathrm{H}-16 \mathrm{OH}$, and $\mathrm{L}$ - and $\mathrm{H}-16 \mathrm{Ac}$. Scale bar, $200 \mu \mathrm{m}$. (K-M) Comparative analyses of the numbers of the c-Fos+ cells in the MeA between different concentrations of $160 \mathrm{H}$ and $16 \mathrm{Ac}$, between sexes or between the two pheromones, respectively. All four stimuli except $\mathrm{L}-16 \mathrm{OH}$ were able to elicit stronger c-Fos immunoreactivity than control in the male MeA whereas in the female MeA, only $\mathrm{H}-16$-Ac was able to do so. $\mathrm{H}-16 \mathrm{OH}$ was significantly more effective than $\mathrm{L}-16 \mathrm{OH}$ on the female MeA whereas $\mathrm{H}-16 \mathrm{Ac}$ was more so than $\mathrm{L}-16 \mathrm{Ac}$ on the male MeA (M-L-16OH vs. M-control, $t=2.278, p=0.075 ; \mathrm{M}-\mathrm{H}-16 \mathrm{OH}$ vs. M-control, $t=3.998, p=0.002 ; \mathrm{M}-\mathrm{L}-16 \mathrm{Ac}$ vs. M-control, $t=4.172, p=0.001 ; \mathrm{M}-\mathrm{H}-16 \mathrm{Ac}$ vs. M-control, $t=9.339, p=0.000 ; \mathrm{F}-\mathrm{L}-16 \mathrm{OH}$ vs. F-control, $t=1.776, p=0.817 ; \mathrm{F}-\mathrm{H}-16 \mathrm{OH}$ vs. F-control, $t=11.134$, $p=0.000 ; \mathrm{F}-\mathrm{L}-16 \mathrm{Ac}$ vs. F-control, $t=1.905, p=0.626 ; \mathrm{F}-\mathrm{H}-16 \mathrm{Ac}$ vs. F-control, $t=2.281, p=0.268 ; \mathrm{F}-\mathrm{H}-16 \mathrm{OH}$ vs. F-L-16OH, $t=9.357, p=0.000 ; \mathrm{M}-\mathrm{H}-16 \mathrm{OH}$ vs. $\mathrm{M}-\mathrm{L}-16 \mathrm{OH}, t=1.210, p=1.000 ; \mathrm{M}-\mathrm{H}-16 \mathrm{Ac}$ vs. M-L-16Ac, $t=5.166, p=0.000 ; \mathrm{F}-\mathrm{H}-16 \mathrm{Ac}$ vs. F-L-16Ac, $t=0.376, p=1.000)$. Female MeA was more responsive to $\mathrm{H}-16 \mathrm{OH}$ whereas male MeA was more so to $\mathrm{H}-16 \mathrm{Ac}$; and $\mathrm{H}-16 \mathrm{OH}$ was more effective than $\mathrm{H}-16 \mathrm{Ac}$ on the female MeA whereas on the male MeA, the opposite was true ( $\mathrm{F}-\mathrm{H}-16 \mathrm{OH}$ vs. M-H-16OH, $t=7.471, p=0.000$; M-H-16Ac vs. F-H-16Ac, $t=6.722, p=0.000 ; \mathrm{F}-\mathrm{L}-16 \mathrm{OH}$ vs. M-L-160H, $t=0.676, p=0.502$; M-L-16Ac vs. F-L-16Ac, $t=1.933, p=0.059 ; \mathrm{F}-\mathrm{H}-160 \mathrm{H}$ vs. F-H-16Ac, $t=8.852, p=0.000 ; \mathrm{M}-\mathrm{H}-16 \mathrm{Ac}$ vs. M-H-16OH, $t=5.341, p=0.000 ; \mathrm{F}-\mathrm{L}-160 \mathrm{H}$ vs. F-L-16Ac, $t=0.128, p=1.000 ; \mathrm{M}-\mathrm{L}-16 \mathrm{Ac}$ vs. $\mathrm{M}-\mathrm{L}-16 \mathrm{OH}, t=1.385, p=1.000) . \mathrm{N}=6$ for each group. All values are expressed as mean $\pm \mathrm{s}$.e.m. ${ }^{* *} p<0.01$, $* * * p<0.001$.
\end{abstract}

\section{Projection of $160 \mathrm{H}$ and 16 Ac Signals to the Accessory Olfactory Bulb}

To determine the projection of $16 \mathrm{OH}$ and $16 \mathrm{Ac}$ signals from the VNO to AOB, we used c-Fos and Gai2 immunostaining to identify and locate the activated neurons to the anterior or posterior half of the AOB (Figure 6). The numbers of c-Fos+ neurons in the $\mathrm{AOB}$ were significantly greater in both male and female mice exposed to both low and high $16 \mathrm{OH}$ and $16 \mathrm{Ac}$ than that in the control mice exposed to $0.01 \%$ DCM-containing mineral oil (Figure 6 and Table 1). In comparison of the c-Fos expression between the two $\mathrm{AOB}$ halves, we found that the aAOB had more c-Fos + neurons than the $\mathrm{pAOB}$ in both male and female mice in response to low and high $16 \mathrm{OH}$ or $16 \mathrm{Ac}$ (Figure 6D and Table 1). Furthermore, H-16OH or H-16Ac evoked more c-Fos-positive neurons than L-16OH or L-16Ac, respectively, in the AOB of the mice of the same sex (Figure 7A).

When the data from the $\mathrm{AAOB}$ and $\mathrm{pAOB}$ were processed separately, we found that $16 \mathrm{OH}$ and $16 \mathrm{Ac}$ induced stronger c-Fos expression at both low and high concentrations than control, except that in the female pAOB, L-16Ac failed to do so. Further, $\mathrm{H}-16 \mathrm{OH}$ and $\mathrm{H}-16 \mathrm{Ac}$ were more effective in eliciting c-Fos responses than their low counterparts in both male and female, aAOB or pAOB (Figures 7B,C).

As for sexual differences, the female AOB had more c-Fos+ cells than the male $\mathrm{AOB}$ in response to both $\mathrm{L}$ - and $\mathrm{H}-16 \mathrm{OH}$ whereas the male AOB had more c-Fos+ cells than the female AOB in response to both L- and H-16Ac. The pattern still held even when the data from the two $\mathrm{AOB}$ halves were analyzed separately: the female aAOB and $\mathrm{pAOB}$ responded significantly stronger than male $\mathrm{aAOB}$ and $\mathrm{pAOB}$ to both $\mathrm{L}$ - and $\mathrm{H}$ $16 \mathrm{OH}$ whereas in response to $\mathrm{L}$ - and $\mathrm{H}-16 \mathrm{Ac}$, male aAOB and pAOB had more c-Fos + neurons than their female counterparts (Figures 7D-F).

Comparative analysis of the efficacy of the two pheromones indicated that on the female $\mathrm{AOB}, \mathrm{L}-$ or $\mathrm{H}-16 \mathrm{OH}$ was more effective than L- or $\mathrm{H}-16 \mathrm{Ac}$ whereas on the male AOB, Lor $\mathrm{H}-16 \mathrm{Ac}$ was more effective than $\mathrm{L}-$ or $\mathrm{H}-16 \mathrm{OH}$. And the pattern was still true if the c-Fos immunostaining data were analyzed for $\mathrm{aAOB}$ and $\mathrm{pAOB}$ separately except the male $\mathrm{pAOB}$ (Figures 7G-I).

Following the initial processing in the AOB, pheromonal signals are known to be sent to the next orders of the neurons in several brain regions, including the BNST, MeA, PMCo, and then from both BNST and amygdaloid nuclei further downstream to the MPA and VmH (Supplementary Figure 1; Dulac and Wagner, 2006). To determine how the $16 \mathrm{OH}$ and 16Ac signals are processed in the higher brain regions, we carried out c-Fos immunohistochemistry on the brain sections containing the aforementioned nuclei to identify the neurons constituting the neural circuitry for these two pheromones.

\section{$160 H$ and $16 A c$ Induce c-Fos Immunoreactivity in the BNST}

After exposure to low and high $16 \mathrm{OH}$ and $16 \mathrm{Ac}$, the male and female mice were examined for the c-Fos-immunoreactivity in the BNST (Figure 8). The results showed that in comparison with the $0.01 \%$ DCM-containing mineral oil-treated control samples, either L-16OH or L-16Ac could evoke significantly more c-Fos signals from male or female BNST where $\mathrm{H}-16 \mathrm{OH}$ and $\mathrm{H}-16 \mathrm{Ac}$ were able to do so on both male and female BNST except $\mathrm{H}$ 16Ac on the female BNST. And $\mathrm{H}-16 \mathrm{OH}$ and $\mathrm{H}-16 \mathrm{Ac}$ induced significantly more c-Fos + cells than their counterparts of the low concentration on both male and female BNST except $\mathrm{H}-16 \mathrm{Ac}$ on the female BNST (Figure 8K and Table $\mathbf{1}$ ).

Comparison between sexes indicates that the female BNST responded more strongly to $\mathrm{H}-16 \mathrm{OH}$ than the male BNST whereas the male BNST did to H-16Ac than the female (Figure 8L). Comparison between the two pheromones indicates that $\mathrm{H}-16 \mathrm{OH}$ was more effective than $\mathrm{H}-16 \mathrm{Ac}$ on the female BNST whereas $\mathrm{H}-16 \mathrm{Ac}$ was more so than $\mathrm{H}-16 \mathrm{OH}$ on the male BNST (Figure 8M).

\section{$160 \mathrm{H}$ and 16Ac Activate Neurons in the Medial Amygdaloid Nucleus}

A major portion of the AOB output is known to be relayed to the MeA. To determine how the neurons in the nucleus are activated by $16 \mathrm{OH}$ and $16 \mathrm{Ac}$, c-Fos immunoreactivity was also examined on the anterior subdivision of this nucleus (Figure 9). The results showed that the c-Fos immunoreactivity pattern mirrored, to some extent, that found in the BNST, e.g., in the male MeA, both L- and $\mathrm{H}-16 \mathrm{Ac}$ and $\mathrm{H}-16 \mathrm{OH}$ were able to elicit more c-Fos immunoreactivity than control, but only $\mathrm{H}-16 \mathrm{Ac}$ was more effective than L-16Ac in the male, whereas, in the female $\mathrm{MeA}$, only $\mathrm{H}-16 \mathrm{OH}$ was able to evoke significantly more c-Fos 
A

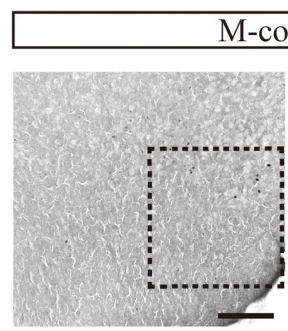

C
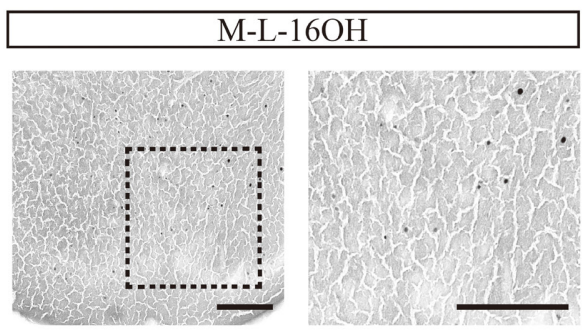

E
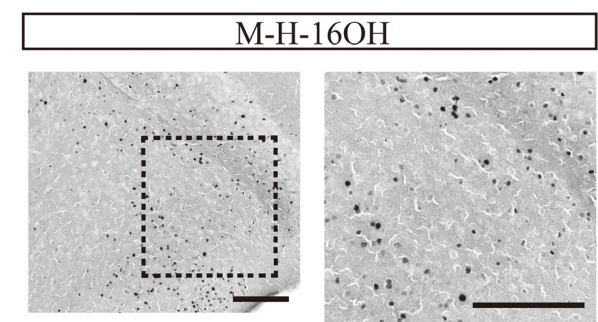

G
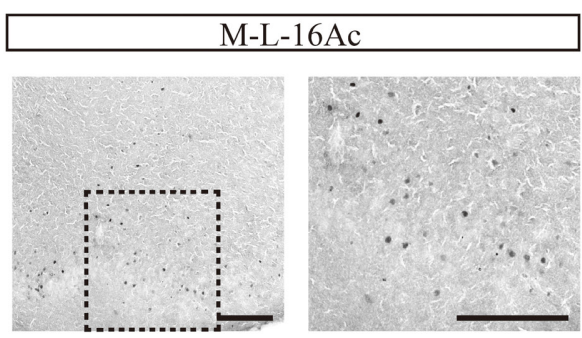

I
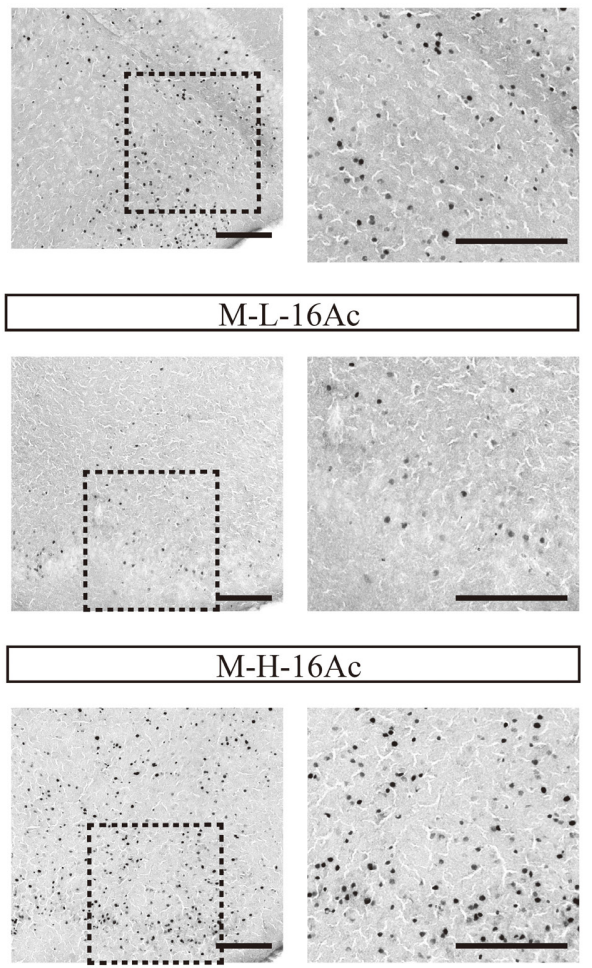

F

K

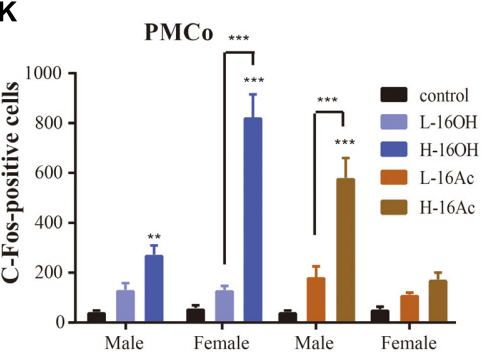

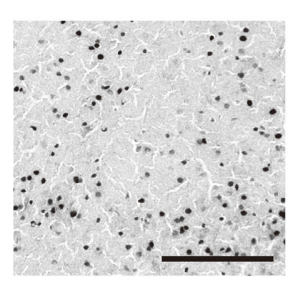

1

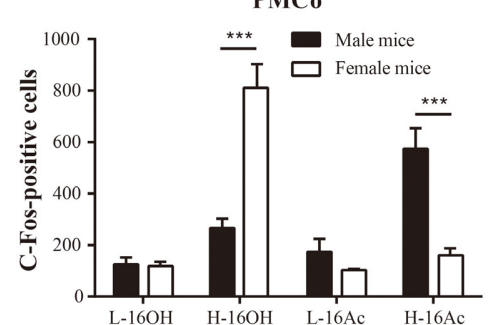

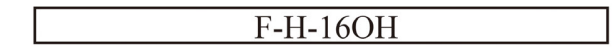

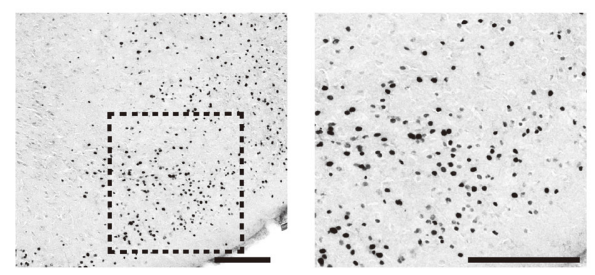

H

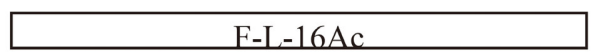

F-control

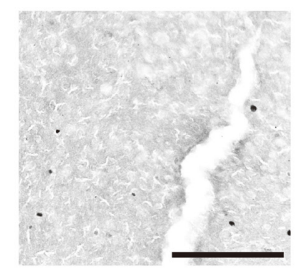

D
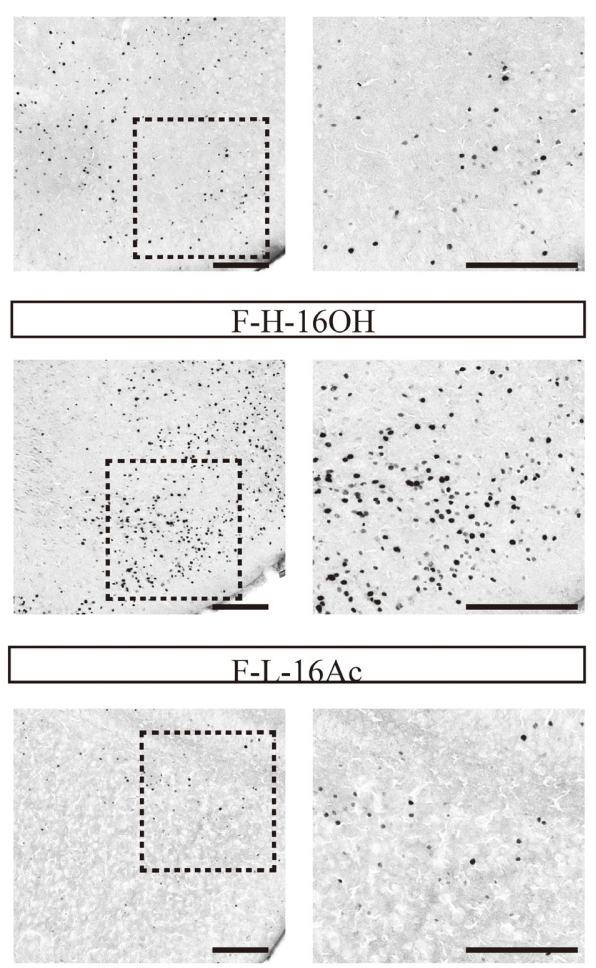

J

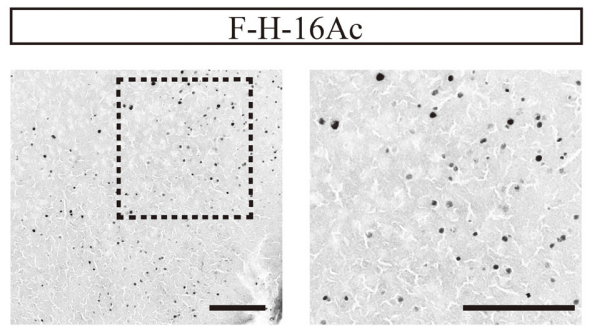

M

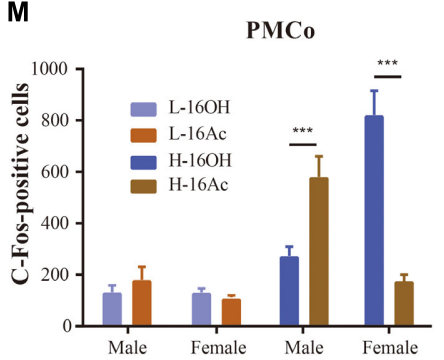

FIGURE 10 | Continued 


\begin{abstract}
FIGURE 10 | Representative images and quantification of the c-Fos+ neurons in the posteromedial cortical amygdaloid nucleus (PMCo). (A-J) Images and their insets of C-Fos-positive cells in the PMCo of male or female mice after exposure to $0.01 \% \mathrm{DCM}$-containing mineral oil (control), $\mathrm{L}$ - and $\mathrm{H}$ - $16 \mathrm{OH}$, and $\mathrm{L}$ - and $\mathrm{H}$ - $16 \mathrm{Ac}$, respectively. Scale bar, $200 \mu \mathrm{m}$. (K) $\mathrm{H}-16 \mathrm{OH}$ but not $\mathrm{L}-16 \mathrm{OH}$ was able to induce more c-Fos signals from both male and female PMCo; and $\mathrm{H}-16 \mathrm{Ac}$ produced significantly more c-Fos signals than control from the male but not female PMCo whereas L-16Ac were ineffective on either male or female PMCo (M-L-16OH vs. $\mathrm{M}$-control, $t=1.384, p=1.000 ; \mathrm{M}-\mathrm{H}-160 \mathrm{H}$ vs. M-control, $t=3.570, p=0.008 ; \mathrm{M}-\mathrm{L}-16 \mathrm{Ac}$ vs. $\mathrm{M}$-control, $t=2.122, p=0.388 ; \mathrm{M}-\mathrm{H}-16 \mathrm{Ac}$ vs. $\mathrm{M}$-control, $t=8.317$, $p=0.000 ; \mathrm{F}-\mathrm{L}-16 \mathrm{OH}$ vs. F-control, $t=1.193, p=1.000 ; \mathrm{F}-\mathrm{H}-16 \mathrm{OH}$ vs. F-control, $t=11.845, p=0.000 ; \mathrm{F}-\mathrm{L}-16 \mathrm{Ac}$ vs. F-control, $t=0.913, p=1.000 ; \mathrm{F}-\mathrm{H}-16 \mathrm{Ac}$ vs. F-control, $t=1.841, p=0.716 ; \mathrm{M}-\mathrm{H}-16 \mathrm{OH}$ vs. M-L-16OH, $t=2.187, p=0.335 ; \mathrm{F}-\mathrm{H}-16 \mathrm{OH}$ vs. F-L-16OH, $t=10.651, p=0.000 ; \mathrm{M}-\mathrm{H}-16 \mathrm{Ac}$ vs. M-L-16Ac, $t=6.194, p=0.000 ; \mathrm{F}-\mathrm{H}-16 \mathrm{Ac}$ vs. F-L-16Ac, $t=0.927, p=1.000)$. (L,M) The female PMCo was more sensitive than the male to $\mathrm{H}-16 \mathrm{OH}$ whereas the male PMCo was more so to $\mathrm{H}-16 \mathrm{Ac}$ than the female; and $\mathrm{H}-16 \mathrm{OH}$ was more effective than $\mathrm{H}-16 \mathrm{Ac}$ on the female MeA whereas on the male MeA, the opposite was true (F-H-16OH vs. M-H-16OH, $t=8.447, p=0.000 ; \mathrm{M}-\mathrm{H}-16 \mathrm{Ac}$ vs. F-H-16Ac, $t=6.303, p=0.000 ; \mathrm{F}-\mathrm{L}-16 \mathrm{OH}$ vs. $\mathrm{M}-\mathrm{L}-160 \mathrm{H}, t=0.0175, p=0.986 ; \mathrm{M}-\mathrm{L}-16 \mathrm{Ac}$ vs. F-L-16Ac, $t=1.037, p=0.305 ; \mathrm{F}-\mathrm{H}-160 \mathrm{H}$ vs. F-H-16Ac, $t=10.004, p=0.000 ; \mathrm{M}-\mathrm{H}-16 \mathrm{Ac}$ vs. M-H-16OH, $t=4.746, p=0.000 ; \mathrm{F}-\mathrm{L}-16 \mathrm{OH}$ vs. F-L-16Ac, $t=0.280, p=1.000 ; \mathrm{M}-\mathrm{L}-16 \mathrm{Ac}$ vs. F-L-16Ac, $t=0.739, p=1.000) . N=6$ for each group. All values are expressed as mean $\pm \mathrm{s} . \mathrm{e} . \mathrm{m}$. ${ }^{* *} p<0.01,{ }^{* * *} p<0.001$.
\end{abstract}

immunoreactivity than control. However, both L-16OH and Land $\mathrm{H}-16 \mathrm{Ac}$ failed to augment c-Fos response in the female MeA. Comparison between sexes or between the two pheromones lead to the similar results as found in the BNST, that is, the female MeA more robustly responded to $\mathrm{H}-16 \mathrm{OH}$ whereas the male MeA did to $\mathrm{H}-16 \mathrm{Ac}$; and $\mathrm{H}-16 \mathrm{OH}$ was more effective than $\mathrm{H}-16 \mathrm{Ac}$ on the female MeA whereas the opposite was true on the male MeA (Figure 9 and Table 1).

\section{$160 \mathrm{H}$ and 16Ac Activate Neurons in the Posteromedial Cortical Amygdaloid Nucleus}

The PMCo is another nucleus that directly receives signals from the AOB. Comparative analyses showed that $\mathrm{H}-16 \mathrm{OH}$ but not L-16OH was able to produce significantly more c-Fos immunoreactivity in both male and female PMCo than control whereas only $\mathrm{H}-16 \mathrm{Ac}$ produced significantly more c-Fos signals than control in the male but not female PMCo with L-16Ac ineffective on either sex. And $\mathrm{H}-16 \mathrm{Ac}$ was more effective than $\mathrm{L}-16 \mathrm{Ac}$ on the male PMCo whereas $\mathrm{H}-16 \mathrm{OH}$ was more so than $\mathrm{L}-16 \mathrm{OH}$ on the female PMCo (Figure 10 and Table 1). Comparison between sexes or between the two pheromones lead to the same results as with the BNST or $\mathrm{MeA}$, that is, the female PMCo was more sensitive to $\mathrm{H}-16 \mathrm{OH}$ whereas the male PMCo was to $\mathrm{H}-16 \mathrm{Ac}$; and $\mathrm{H}$ $16 \mathrm{OH}$ was more effective than $\mathrm{H}-16 \mathrm{Ac}$ on the female PMCo whereas the opposite was true on the male PMCo (Figure 10 and Table 1).

\section{$160 \mathrm{H}$ and 16Ac Activate Neurons in the Medial Preoptic Area}

The MPA is known to receive signals from both the BNST and MeA. To determine whether $16 \mathrm{OH}$ and $16 \mathrm{Ac}$ also activate the neurons in this nucleus, we performed c-Fos immunostaining and analyzed the data (Figure 11). The results showed that both male and female mice generated significantly more c-Fos immunoreactivity in the nuclei following the exposure to L$16 \mathrm{OH}, \mathrm{H}-16 \mathrm{OH}$, or $\mathrm{H}-16 \mathrm{Ac}$ than the control (Figure 11 and Table 1). Furthermore, $\mathrm{H}-16 \mathrm{OH}$ evoked more immunoreactivity than $\mathrm{L}-16 \mathrm{OH}$ in the female but not male MPA while $\mathrm{H}-16 \mathrm{Ac}$ was not significantly more effective than L-16Ac on either male or female MPA. Comparison between sexes indicated that the female MPA was more sensitive to $\mathrm{H}-16 \mathrm{OH}$ than its male counterpart while the opposite was true in response to $\mathrm{H}-16 \mathrm{Ac}$. Comparison between the two pheromones indicated that only $\mathrm{H}-16 \mathrm{OH}$ was more effective than $\mathrm{H}-16 \mathrm{Ac}$ on the female MPA and no any other significant differences were found (Figure 11).

\section{$160 \mathrm{H}$ and 16Ac Activate Neurons in the Ventromedial Hypothalamic Nuclei}

The signals from the MPA are known to be relayed to the VmH. c-Fos immunoreactivity analyses showed that the response patterns were nearly identical to those found in the MPA, that is, all stimulations, L- or $\mathrm{H}-16 \mathrm{OH}, \mathrm{L}-$ or $\mathrm{H}-16 \mathrm{Ac}$ generated more c-Fos signals than control on both male and female $\mathrm{VmH}$ (Figure 12 and Table 1). But the concentration-dependent increases in c-Fos signals were found for $16 \mathrm{OH}$ on both male and female $\mathrm{VmH}$ only. The female $\mathrm{VmH}$ was more sensitive than the male $\mathrm{VmH}$ to $\mathrm{H}-16 \mathrm{OH}$ whereas the opposite was true to $\mathrm{H}$ 16 Ac. $\mathrm{H}-16 \mathrm{OH}$ was more effective than $\mathrm{H}-16 \mathrm{Ac}$ on the female $\mathrm{VmH}$ (Figure 12).

\section{DISCUSSION}

The mammalian olfactory system is comprised of two subsystems: the MOS and the AOS. While the former is mainly responsible for detecting volatile odorants, the latter is largely for detecting less or non-volatile pheromones, although some cross-detections between these two have been reported as well (Holy, 2018; Mohrhardt et al., 2018). Unlike a relatively large number of odorants and their corresponding olfactory receptors, very few pheromones or their receptors have been structurally identified or deorphanized. Hexadecanol $(16 \mathrm{OH})$ and hexadecyl acetate (16Ac) are two semi-volatile and rare chemically pure pheromones that exert differential effects on male and female mice (Zhang et al., 2008). In-depth studies on these two pheromones can facilitate our understanding of the AOS mechanisms.

Calcium imaging of the VNO slices indicated that a small percentage $(0.6-1.9 \%)$ of male and female VSNs responded to $16 \mathrm{OH}$ only, 16Ac only, or both $16 \mathrm{OH}$ and 16Ac (Figures 1-4), which is very similar to the percentages of VSNs activated by several other known pheromones, including the small molecules: 2,5-dimethypyrazine, SBT, 2,3-dehydro-exobrevicomin, $\alpha$ - and $\beta$-farnesenes, 2-heptanone, and $\mathrm{HMH}$, 
A

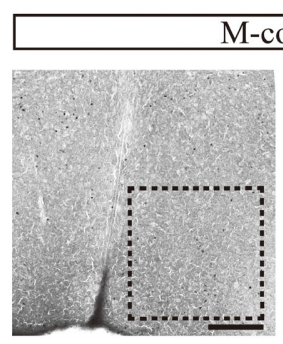

c
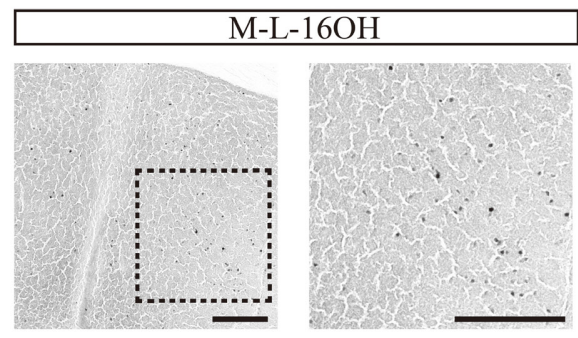

E
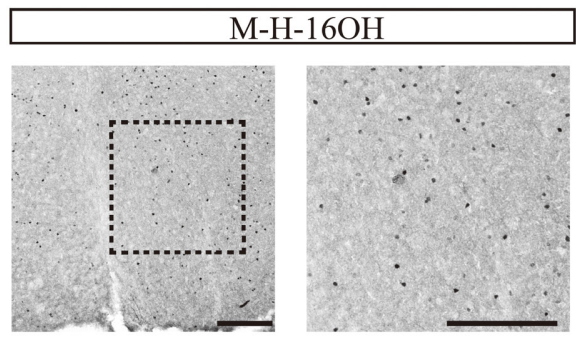

G
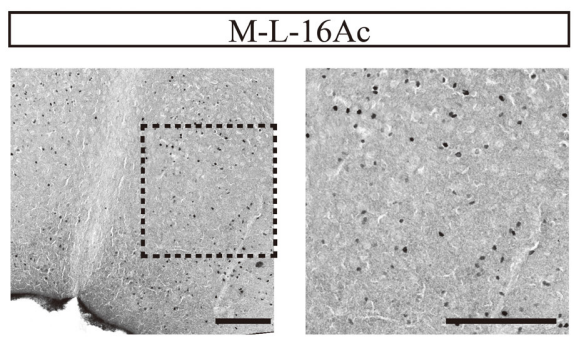

I
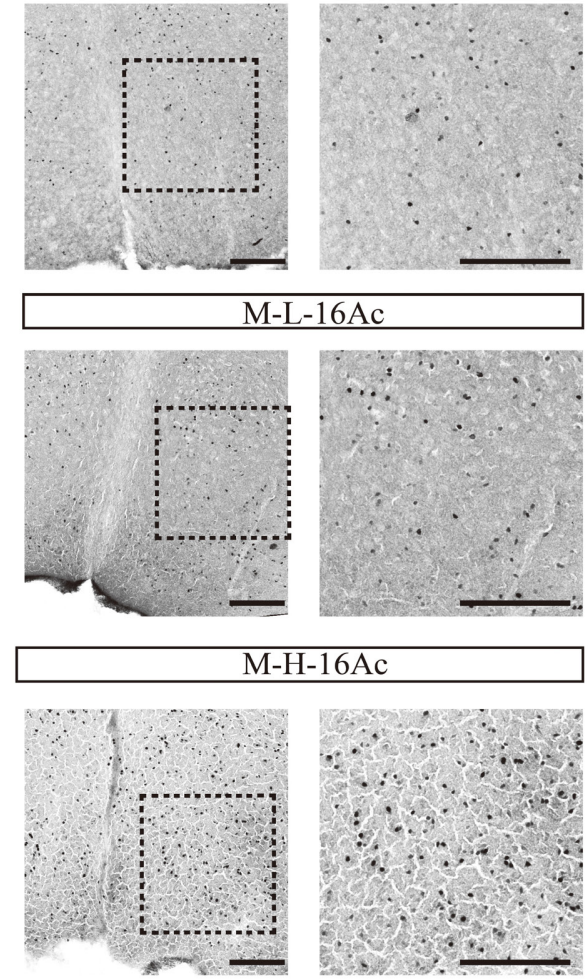

$\mathrm{H}$

H
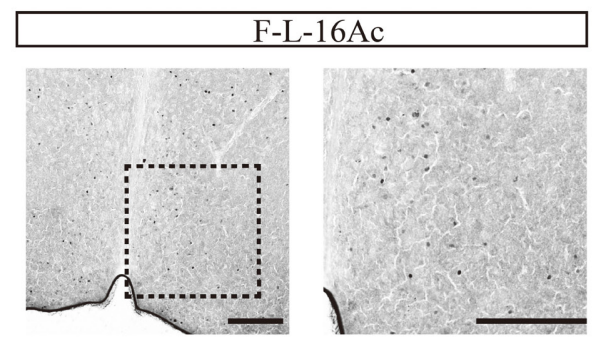

J
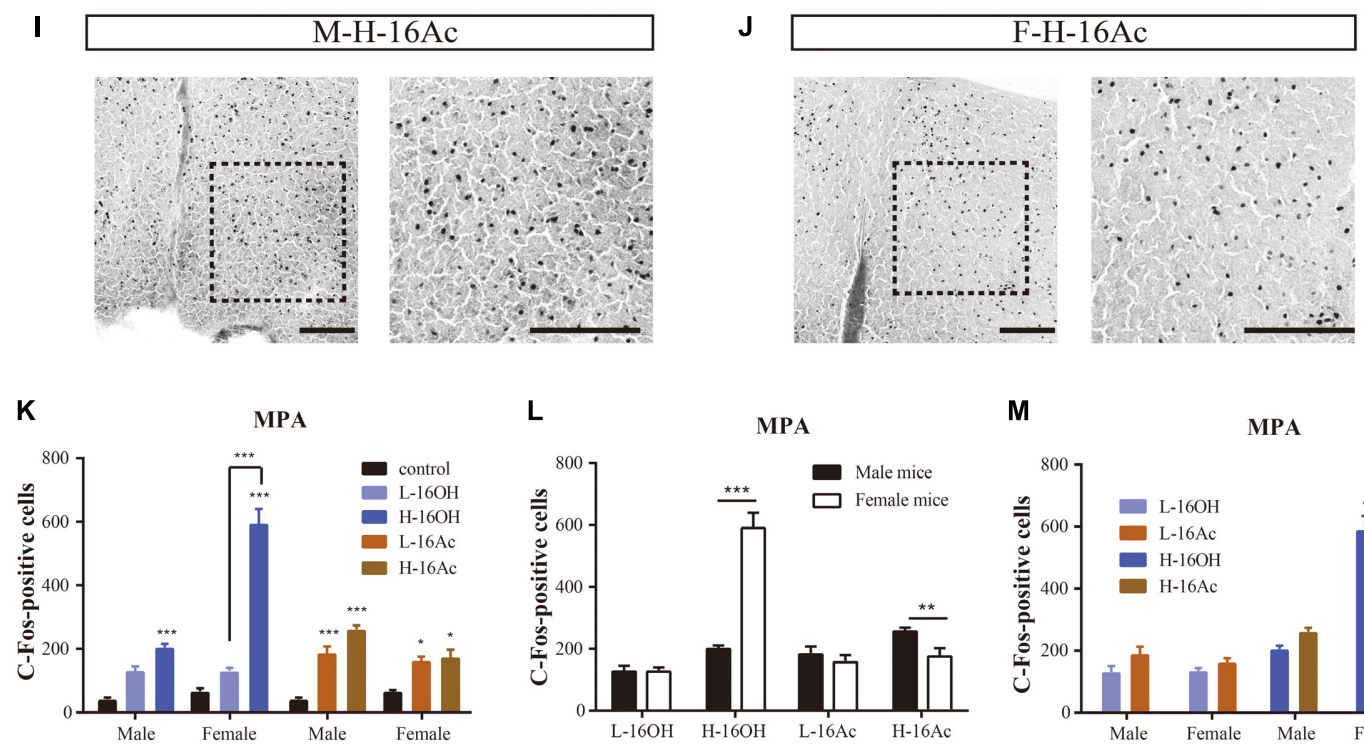

M

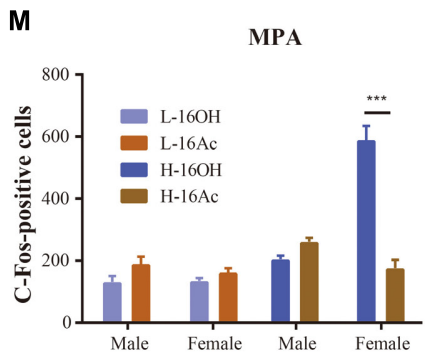

FIGURE 11 | Continued 


\begin{abstract}
FIGURE 11 | Representative images and quantification of C-Fos+ neurons in the medial preoptic area (MPA). (A-J) Images and their insets of C-Fos+ cells in MPA of male or female mice after exposure to $0.01 \%$ DCM-containing mineral oil (control), L- and $\mathrm{H}-16 \mathrm{OH}$, and L- and $\mathrm{H}-16 \mathrm{Ac}$, respectively. Scale bar, $200 \mathrm{\mu m}$. (K-M) Comparative analysis of the c-Fos data between different concentrations of the pheromones, between sexes, and between the two pheromones, respectively. All four stimuli except $\mathrm{L}-16 \mathrm{OH}$ induced significantly more c-Fos+ cells in the male and female MPA; and $\mathrm{H}-16 \mathrm{OH}$ evoked more than $\mathrm{L}-16 \mathrm{OH}$ on the female but not male MPA whereas $\mathrm{H}-16 \mathrm{Ac}$ did not elicit more c-Fos+ cells than $\mathrm{L}-16 \mathrm{Ac}$ in the MPA of either sex (M-L-16OH vs. M-control, $t=2.833, p=0.058 ; \mathrm{M}-\mathrm{H}-16 \mathrm{OH}$ vs. $\mathrm{M}$-control, $t=5.266, p=0.000 ; \mathrm{M}-\mathrm{L}-16 \mathrm{Ac}$ vs. M-control, $t=4.658, p=0.000 ; \mathrm{M}-\mathrm{H}-16 \mathrm{Ac}$ vs. M-control, $t=7.038, p=0.000 ; \mathrm{F}-\mathrm{L}-16 \mathrm{OH}$ vs. F-control, $t=2.069$, $p=0.438 ; \mathrm{F}-\mathrm{H}-16 \mathrm{OH}$ vs. F-control, $t=16.756, p=0.000 ; \mathrm{F}-\mathrm{L}-16 \mathrm{Ac}$ vs. F-control, $t=3.036, p=0.038 ; \mathrm{F}-\mathrm{H}-16 \mathrm{Ac}$ vs. F-control, $t=3.458, p=0.010 ; \mathrm{M}-\mathrm{H}-16 \mathrm{OH}$ vs. $\mathrm{M}-\mathrm{L}-16 \mathrm{OH}, t=2.343, p=0.231 ; \mathrm{F}-\mathrm{H}-16 \mathrm{OH}$ vs. F-L-16OH, $t=14.687, p=0.000 ; \mathrm{M}-\mathrm{H}-16 \mathrm{Ac}$ vs. $\mathrm{M}-\mathrm{L}-16 \mathrm{Ac}, t=2.381, p=0.211 ; \mathrm{F}-\mathrm{H}-16 \mathrm{Ac}$ vs. F-L-16Ac, $t=0.448, p=1.000) . \mathrm{H}-16 \mathrm{OH}$ was more effective on the female MPA than on the male MPA whereas $\mathrm{H}-16 \mathrm{Ac}$ was more so on the male MPA than on the female one $(\mathrm{F}-\mathrm{H}-16 \mathrm{OH}$ vs. $\mathrm{M}-\mathrm{H}-16 \mathrm{OH}, t=12.348, p=0.000 ; \mathrm{M}-\mathrm{H}-16 \mathrm{Ac}$ vs. F-H-16Ac, $t=2.735, p=0.009 ; \mathrm{F}-\mathrm{L}-16 \mathrm{OH}$ vs. $\mathrm{M}-\mathrm{L}-160 \mathrm{H}, t=0.00426, p=0.997 ; \mathrm{M}-\mathrm{L}-16 \mathrm{Ac}$ vs. F-L-16Ac, $t=0.803, p=0.426)$. And $\mathrm{H}-16 \mathrm{OH}$ seemed to be more effective than $\mathrm{H}-16 \mathrm{Ac}$ on the female MPA (M-L-16OH vs. $\mathrm{M}-\mathrm{L}-16 \mathrm{Ac}, t=1.775, p=0.820$; $\mathrm{M}-\mathrm{H}-16 \mathrm{OH}$ vs. $\mathrm{M}-\mathrm{H}-16 \mathrm{Ac}, t=1.812, p=0.760 ; \mathrm{F}-\mathrm{L}-16 \mathrm{OH}$ vs. $\mathrm{F}-\mathrm{L}-16 \mathrm{Ac}, t=0.968, p=1.000 ; \mathrm{F}-\mathrm{H}-16 \mathrm{OH}$ vs. F-H-16Ac, $t=13.271, p=0.000)$. $N=6$ for each group. All values are expressed as mean \pm s.e.m. ${ }^{*} p<0.05,{ }^{* *} p<0.01,{ }^{* * *} p<0.001$
\end{abstract}

and the large molecules such as peptides ESPs and major urine proteins (Leinders-Zufall et al., 2000; Kimoto et al., 2007; Ferrero et al., 2013; Dey et al., 2015). Notably, only one vomeronasal receptor has been identified for each of these pheromones: Vmn1r49 for 2-heptanone, Vmn2r116 for ESP1, and V2Rp4 for ESP22 (Boschat et al., 2002; Haga et al., 2010; Osakada et al., 2018). Thus, given the similar percentages of the activated VSNs, we conclude that it is likely only one vomeronasal receptor each for detecting $16 \mathrm{OH}, 16 \mathrm{Ac}$, or both.

Further, our data also showed that the VSNs responsive to $16 \mathrm{OH}, 16 \mathrm{Ac}$, or both were preferentially located in the apical VSE, and that the numbers of responsive neurons did not increase in most cases even when the pheromone concentrations were raised by 10,000 -fold, from $10 \mathrm{nM}$ to $100 \mu \mathrm{M}$, with one exception of the female VSNs that significantly increased by twofold upon stimulation of $100 \mu \mathrm{M} 16 \mathrm{OH}$, i.e., $\mathrm{H}-16 \mathrm{OH}$ (Figures 2-5). These results indicate that probably there is only one V1r in the male and female VSE sensing $16 \mathrm{OH}, 16 \mathrm{Ac}$, or both, respectively, whereas the female VSNs may express an additional V1r for detecting the high concentration of $16 \mathrm{OH}$. On the other hand, however, the basal VSNs also responded, to a lesser extent, to these chemicals. Thus, it is also possible that there is another $\mathrm{V} 2 \mathrm{r}$ responsive to each of $16 \mathrm{OH}$ and $16 \mathrm{Ac}$ or both, respectively.

The pheromonal signals detected by VSNs are then projected to the AOB. Our c-Fos immunostaining data indicate that significantly more c-Fos+ neurons were found in the aAOB than in the pAOB (Figure 6), which is in congruency with the calcium imaging data showing the apical location of most responsive VSNs (Figure 5). However, the male pAOB responded to all four stimuli: $\mathrm{L}-$ and $\mathrm{H}-16 \mathrm{OH}, \mathrm{L}-$ and $\mathrm{H}-$ 16Ac whereas the female $\mathrm{pAOB}$ did to three of the four: Land $\mathrm{H}-16 \mathrm{OH}$, and $\mathrm{H}-16 \mathrm{Ac}$, but not to L-16Ac (Figure 7), which is also consistent with the VNO results showing calcium responses also from the basal VSNs to $16 \mathrm{OH}$ and $16 \mathrm{Ac}$, or both, supporting the idea of $\mathrm{V} 2 \mathrm{r}$ responsive to these two pheromones.

The numbers of male and female c-Fos+ neurons in the AOB, aAOB, or $\mathrm{pAOB}$ were $16 \mathrm{OH}$ and $16 \mathrm{Ac}$ dosedependent (Figure 7), which is different from the observation on the VSE, of which only the number of the female $16 \mathrm{OH}$ responding VSNs was $16 \mathrm{OH}$ concentration-dependent.
This discrepancy may be explained by the fact that VSN firing rates vary from 2.5 to $80 \mathrm{~Hz}$ (Stowers et al., 2002; Nodari et al., 2008; Kim et al., 2012), and that individual VSNs innervate multiple $\mathrm{AOB}$ glomeruli; conversely, some individual glomeruli receive projections from multiple VSNs expressing different vomeronasal receptors (Belluscio et al., 1999; Rodriguez et al., 1999; Wagner et al., 2006), although a mitral cell tends to receive inputs from different glomeruli that are innervated by sensory neurons expressing the same type of V1r or V2r receptor (Del Punta et al., 2002). Thus, high concentrations of $16 \mathrm{OH}$ and $16 \mathrm{Ac}$ may trigger more spikes from VSNs, increasing firing rate, which cannot be detected by the VSN calcium imaging, but activate more glomeruli, generating more c-Fos+ AOB neurons. Further studies, however, are needed to validate this notion.

Mitral cells in the AOB send their axons to other AOS circuit hubs in the brain. Interestingly, the BNST receives inputs only from the aAOB, not from pAOB (MartinezMarcos and Halpern, 1999; Mohedano-Moriano et al., 2007). The c-Fos immunoreactivity pattern in the BNST was closely similar to that in the AOB: the male BNST exhibited significantly more c-Fos+ neurons in response to $\mathrm{H}-16 \mathrm{OH}$ and $\mathrm{H}-16 \mathrm{Ac}$ whereas the female BNST showed significant responses to $\mathrm{H}-16 \mathrm{OH}$ (Figure 8). These results indicate that the information is relayed largely intact from the $\mathrm{AOB}$ to $\mathrm{BNST}$ in response to the high concentration of $16 \mathrm{OH}$ or $16 \mathrm{Ac}$.

Mitral cells in the $\mathrm{AOB}$ can also send axons to the MeA and PMCo, followed by the projection of BNST and MeA neurons to the MPA, and finally to the $\mathrm{VmH}$. The overall profiles of c-Fos immunoreactivity in these nuclei were similar to that found in the BNST, and can be summarized as following: (1) dose-dependency: stronger c-Fos responses were induced by higher concentrations of $16 \mathrm{OH}$ and $16 \mathrm{Ac}$ than lower ones, respectively; (2) sexual dimorphism: the female nuclei responded more strongly to $16 \mathrm{OH}$ whereas male nuclei did so to $16 \mathrm{Ac}$; and (3) the relative effectiveness between the two pheromones: significant differences in evoking c-Fos responses in the nuclei were found between the two pheromones only at their high concentrations but not at the low concentrations. There are, however, some subtle variations. For example, the female MeA exhibited 
A
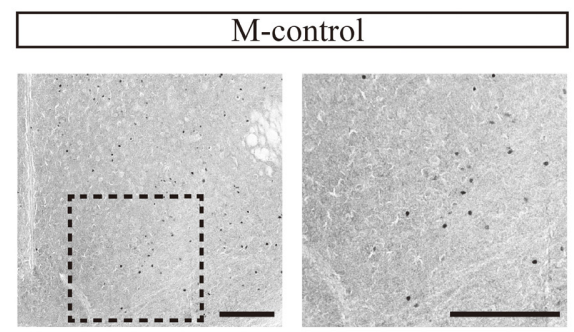

C

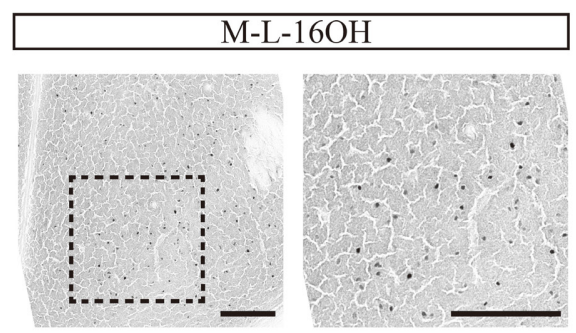

E

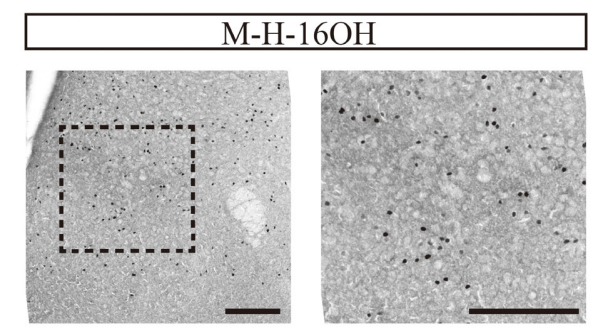

G
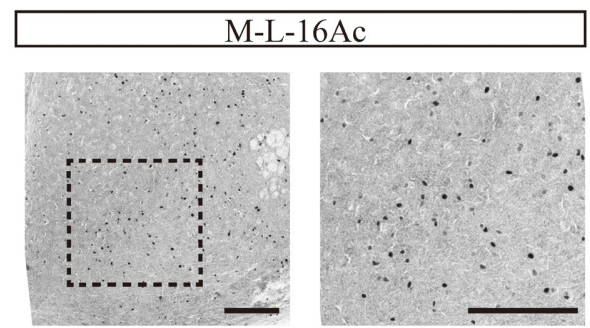

I
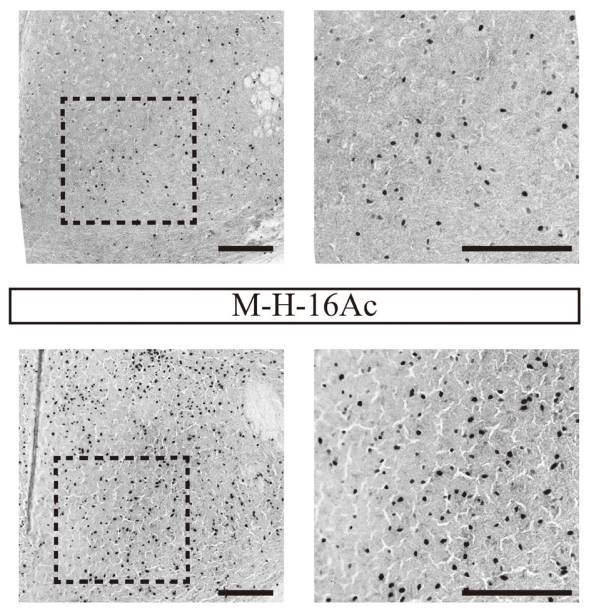

B

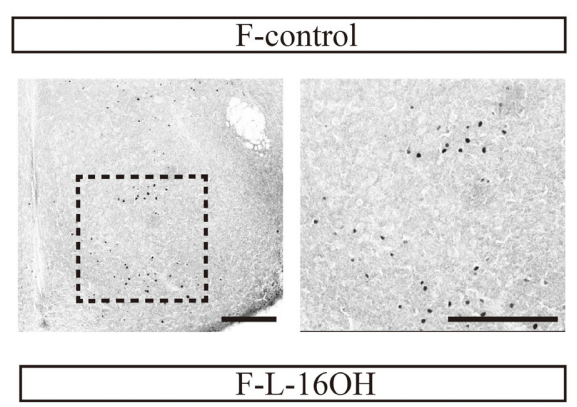

D

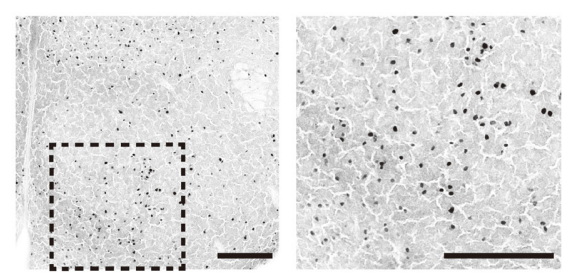

$\mathbf{F}$

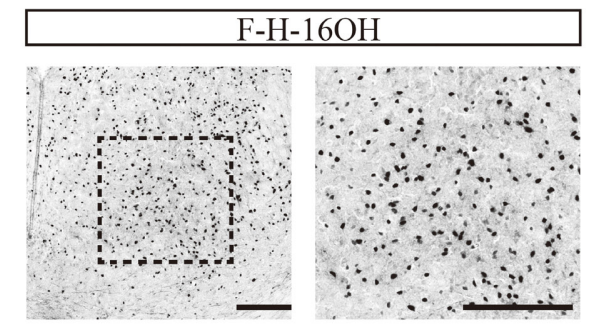

H
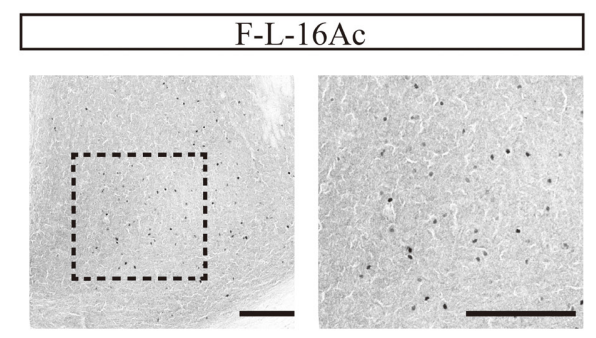

$\mathbf{J}$
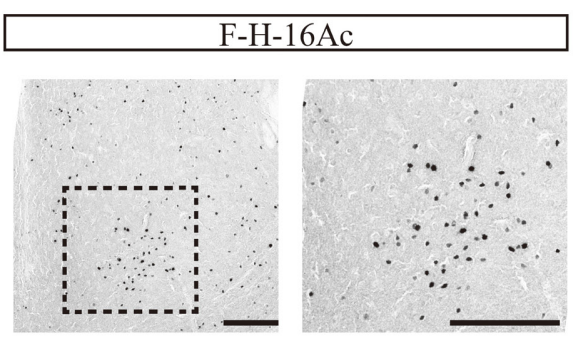
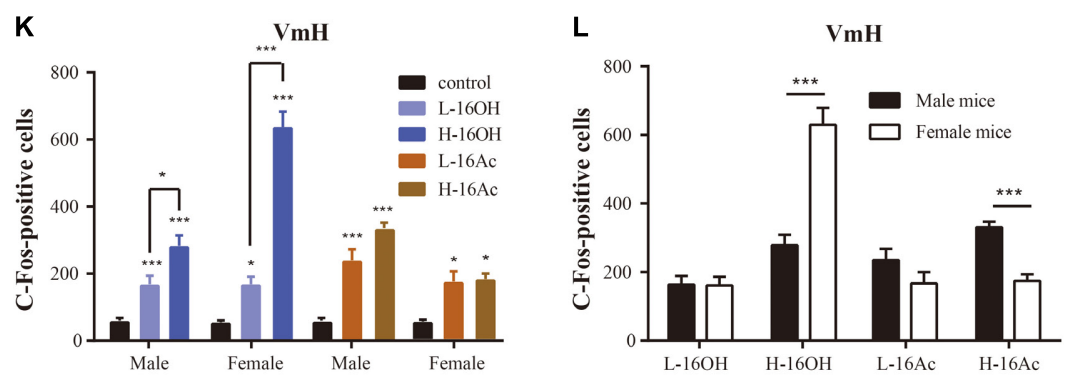

M

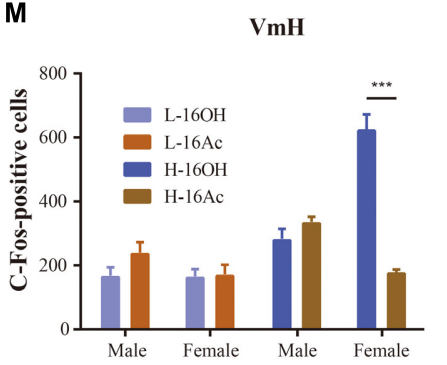

FIGURE 12 | Continued 
FIGURE 12 | Representative images and quantification of the c-Fos+ neurons in the ventromedial hypothalamic nucleus (VmH). (A-J) Images and their insets of c-Fos+ cells in the $\mathrm{VmH}$ of male or female mice after exposure to $0.01 \% \mathrm{DCM}$-containing mineral oil (control), $\mathrm{L}-$ and $\mathrm{H}$ - $16 \mathrm{OH}$, and $\mathrm{L}$ - and $\mathrm{H}$ - $16 \mathrm{Ac}$. Scale bar, $200 \mu \mathrm{m}$. (K) L-16OH, $\mathrm{H}-16 \mathrm{OH}, \mathrm{L}-16 \mathrm{Ac}$, or $\mathrm{H}-16 \mathrm{Ac}$ generated more c-Fos signals than the control on both male and female $\mathrm{VmH}$; $\mathrm{H}$-16OH was more effective than $\mathrm{L}-16 \mathrm{OH}$ on both male and female $\mathrm{VmH}$ whereas $\mathrm{H}-16 \mathrm{Ac}$ did not elicit more c-Fos signals than $\mathrm{L}-16 \mathrm{Ac}$ on either male or female $\mathrm{VmH}$ (M-L-16OH vs. M-control, $t=2.965, p=0.000 ; \mathrm{M}-\mathrm{H}-16 \mathrm{OH}$ vs. M-control, $t=6.602, p=0.000 ; \mathrm{M}-\mathrm{L}-16 \mathrm{Ac}$ vs. M-control, $t=4.892, p=0.000 ; \mathrm{M}-\mathrm{H}-16 \mathrm{Ac}$ vs. $\mathrm{M}-\mathrm{control}, t=7.509, p=0.000 ;$ F-L-16OH vs. F-control, $t=3.082, p=0.032 ; \mathrm{F}-\mathrm{H}-16 \mathrm{OH}$ vs. F-control, $t=15.797, p=0.000 ; \mathrm{F}-\mathrm{L}-16 \mathrm{Ac}$ vs. F-control, $t=3.243, p=0.021 ; \mathrm{F}-\mathrm{H}-16 \mathrm{Ac}$ vs. F-control, $t=3.435, p=0.012 ; \mathrm{M}-\mathrm{H}-16 \mathrm{OH}$ vs. M-L-16OH; $t=3.097, p=0.032 ; \mathrm{F}-\mathrm{H}-16 \mathrm{OH}$ vs. F-L-16OH, $t=12.715, p=0.000 ; \mathrm{M}-\mathrm{H}-16 \mathrm{Ac}$ vs. M-L-16Ac, $t=2.617$, $p=0.117$; F-H-16Ac vs. F-L-16Ac, $t=0.192, p=1.000)$. (L, M) The female $\mathrm{VmH}$ was more responsive than the male $\mathrm{VmH}$ to $\mathrm{H}-16 \mathrm{OH}$ whereas the opposite was true to $\mathrm{H}-16 \mathrm{Ac}$. $\mathrm{H}-16 \mathrm{OH}$ was more effective than $\mathrm{H}-16 \mathrm{Ac}$ on the female $\mathrm{VmH}(\mathrm{F}-\mathrm{H}-16 \mathrm{OH}$ vs. $\mathrm{M}-\mathrm{H}-16 \mathrm{OH}, t=9.543, p=0.000 ; \mathrm{M}-\mathrm{H}-16 \mathrm{Ac}$ vs. $\mathrm{F}-\mathrm{H}-16 \mathrm{Ac}, t=4.266$, $p=0.000 ; \mathrm{F}-\mathrm{L}-16 \mathrm{OH}$ vs. $\mathrm{M}-\mathrm{L}-16 \mathrm{OH}, t=0.0751, p=0.940 ; \mathrm{F}-\mathrm{L}-16 \mathrm{Ac}$ vs. $\mathrm{M}-\mathrm{L}-16 \mathrm{Ac}, t=1.841, p=0.072 ; \mathrm{F}-\mathrm{H}-16 \mathrm{OH}$ vs. F-H-16Ac, $t=12.362, p=0.000 ;$ $\mathrm{M}-\mathrm{H}-16 \mathrm{OH}$ vs. $\mathrm{M}-\mathrm{H}-16 \mathrm{Ac}, t=1.447, p=1.000 ; \mathrm{F}-\mathrm{L}-16 \mathrm{OH}$ vs. F-L-16Ac, $t=0.161, p=1.000 ; \mathrm{M}-\mathrm{L}-16 \mathrm{OH}$ vs. $\mathrm{M}-\mathrm{L}-16 \mathrm{Ac}, t=1.927, p=0.596) . \quad N=6$ for each group. All values are expressed as mean \pm s.e.m. ${ }^{*} p<0.05,{ }^{* * *} p<0.001$.

insignificant increases in the number of c-Fos+ neurons in response to not only $\mathrm{L}$ - or $\mathrm{H}-16 \mathrm{Ac}$ but also $\mathrm{L}-16 \mathrm{OH}$, as in the BNST and PMCo (Figures 9, 10), whereas the male BNST and PMCo nuclei did not respond to $\mathrm{L}-16 \mathrm{OH}$ or L16Ac. In the MPA and $\mathrm{VmH}$, males responded equally to $\mathrm{H}-16 \mathrm{OH}$ and $\mathrm{H}-16 \mathrm{Ac}$.

Neurons in the nuclei examined so far in this study are involved in various pheromone-induced activities. For example, activation of some BNST neurons can suppress female sexual behavior (Osakada et al., 2018), and even the PMCo, which does not have much direct connections to the hypothalamic nuclei, process and relay most information from the $\mathrm{AOB}$ to the $\mathrm{MeA}$ and posterolateral amygdaloid cortex (Gutierrez-Castellanos et al., 2014). The MeA, which receives excitatory signals from the $\mathrm{AOB}$ and the PMCo, sends axons to different amygdala and hypothalamic areas, directing sex-specific behavioral responses as well as endocrine and autonomic responses (Brennan and Zufall, 2006; Ishii et al., 2017). The MPA is known to be critical to control inter-male and pup-directed aggression, sexual behaviors, and parental care (Wu et al., 2014; Wei et al., 2018). Finally, some neurons in the $\mathrm{VmH}$ are involved in initiating aggression, parental caring, and mating as well (Lin et al., 2011; Kohl et al., 2018). However, the only documented behavioral responses induced by $16 \mathrm{OH}$ and $16 \mathrm{Ac}$ include attraction and aversion, with no evident aggression, mating, or parental caring observed yet (Zhang et al., 2008). Our c-Fos data indicate that $16 \mathrm{OH}$ - and $16 \mathrm{Ac}$-activated neurons in the brain regions can be parts of the AOS circuit hubs, contributing to the modulation or fine-tuning of the behavioral outputs determined by these ensembles of neurons (Li et al., 2017; Li and Dulac, 2018). Further investigations are needed to unravel the exact roles played by the $16 \mathrm{OH}$ and 16Ac-activated neurons in the population coding of the pheromonal signals.

Like many other pheromones, $16 \mathrm{OH}$ and $16 \mathrm{Ac}$ also evoke sexually dimorphic responses. In the VNO, similar numbers of male VSNs responded to both $16 \mathrm{OH}$ and 16Ac; in contrast, many more female VSNs did to $16 \mathrm{OH}$ than to 16Ac (Figures 1-3); and upon stimulation of $\mathrm{H}$ $16 \mathrm{OH}$, far more VSNs were activated in females than in males (Figures 4, 5). In the $\mathrm{AOB}$ and most other brain regions, it seems largely consistent that males responded more strongly to $16 \mathrm{Ac}$, females more strongly to $16 \mathrm{OH}$, especially at the high concentration, except in the male MPA and $\mathrm{VmH}$ (Figures 6-12). It is known that AOS brain regions between sexes differ in neuron numbers and sex hormone receptor expression ( $\mathrm{Li}$ and Dulac, 2018). The AOS can be modulated by the inputs from the MOS, by physiological states and experiences. For example, the enzyme aromatase can convert testosterone into estrogen, which acts on the neurons expressing the estrogen receptors, modulating their activity, while mating experience makes a subset of male MeA neurons more responsive (Dey et al., 2015; Xu et al., 2016; Lischinsky et al., 2017). Additional studies are needed to reveal the behavioral and physiological consequences resulted from or modulated by $16 \mathrm{OH}$ and $16 \mathrm{Ac}$ sexual dimorphic effects.

\section{CONCLUSION}

In conclusion, our study demonstrates the activation of VSNs by $16 \mathrm{OH}$ and 16Ac, and the activation of neurons in the circuit hubs of the AOS in a sexually dimorphic manner. Our data indicate that there is one V1r each for $16 \mathrm{OH}, 16 \mathrm{Ac}$, or both, and possibly another $\mathrm{V} 1 \mathrm{r}$ for the concentrated $16 \mathrm{OH}$. And activation of the neurons in the brain regions strongly suggests that $16 \mathrm{OH}$ and $16 \mathrm{Ac}$ can modulate the AOS outputs such as aggression, mating, and parental caring. Further studies on these two abundantly produced and chemically identified natural pheromones can facilitate our understanding of this ancient and vital system in many mammals.

\section{DATA AVAILABILITY STATEMENT}

All datasets generated for this study are included in the manuscript/Supplementary Files.

\section{ETHICS STATEMENT}

The animal study was reviewed and approved by the Institutional Animal Care and Use Committees of both the Zhejiang University and the Institute of Zoology, Chinese Academy of Sciences. 


\section{AUTHOR CONTRIBUTIONS}

QL, J-XZ, and LH designed the experiments, analyzed and interpreted the data, and wrote the manuscript. QL, XG, PW, YZ, and YW performed the experiments.

\section{FUNDING}

This work was supported by the National Natural Science Foundation of China (Nos. 81671016, 31627801, and 31661143030), the Strategic Priority Research Program of the

\section{REFERENCES}

Akiyoshi, S., Ishii, T., Bai, Z., and Mombaerts, P. (2018). Subpopulations of vomeronasal sensory neurons with coordinated coexpression of type 2 vomeronasal receptor genes are differentially dependent on Vmn2r1. Eur. J. Neurosci. 47, 887-900. doi: 10.1111/ejn.13875

Belluscio, L., Koentges, G., Axel, R., and Dulac, C. (1999). A map of pheromone receptor activation in the mammalian brain. Cell 97, 209-220. doi: 10.1016/ s0092-8674(00)80731-x

Boschat, C., Pelofi, C., Randin, O., Roppolo, D., Luscher, C., Broillet, M. C., et al. (2002). Pheromone detection mediated by a V1r vomeronasal receptor. Nat. Neurosci. 5, 1261-1262. doi: 10.1038/nn978

Brechbühl, J., Luyet, G., Moine, F., Rodriguez, I., and Broillet, M.-C. (2011). Imaging pheromone sensing in a mouse vomeronasal acute tissue slice preparation. J. Vis. Exp. 58:e3311. doi: 10.3791/3311

Brennan, P. A., and Zufall, F. (2006). Pheromonal communication in vertebrates. Nature 444, 308-315. doi: 10.1038/nature05404

Del Punta, K., Puche, A., Adams, N. C., Rodriguez, I., and Mombaerts, P. (2002). A divergent pattern of sensory axonal projections is rendered convergent by second-order neurons in the accessory olfactory bulb. Neuron 35, 1057-1066. doi: 10.1016/s0896-6273(02)00904-2

Dey, S., Chamero, P., Pru, J. K., Chien, M. S., Ibarra-Soria, X., Spencer, K. R., et al. (2015). Cyclic regulation of sensory perception by a female hormone alters behavior. Cell 161, 1334-1344. doi: 10.1016/j.cell.2015.04.052

Doyle, W. I., Dinser, J. A., Cansler, H. L., Zhang, X., Dinh, D. D., Browder, N. S., et al. (2016). Faecal bile acids are natural ligands of the mouse accessory olfactory system. Nat. Commun. 7:11936. doi: 10.1038/ncomms11936

Dulac, C., and Torello, A. T. (2003). Molecular detection of pheromone signals in mammals: from genes to behaviour. Nat. Rev. Neurosci. 4, 551-562. doi: $10.1038 / \mathrm{nrn} 1140$

Dulac, C., and Wagner, S. (2006). Genetic analysis of brain circuits underlying pheromone signaling. Ann. Rev. Genet. 40, 449-467. doi: 10.1146/annurev. genet.39.073003.093937

Fabianová, K., Martončíková, M., Fabian, D., Blaško, J., and Račeková, E. (2014). Diverse effect of different odor stimuli on behavior and Fos protein production in the olfactory system neurogenic region of adult rats. Behav. Brain Res. 265(Suppl. C), 38-48. doi: 10.1016/j.bbr.2014.01.023

Ferrero, D. M., Moeller, L. M., Osakada, T., Horio, N., Li, Q., Roy, D. S., et al. (2013). A juvenile mouse pheromone inhibits sexual behaviour through the vomeronasal system. Nature 502, 368-371. doi: 10.1038/nature 12579

Gutierrez-Castellanos, N., Pardo-Bellver, C., Martinez-Garcia, F., and Lanuza, E. (2014). The vomeronasal cortex - afferent and efferent projections of the posteromedial cortical nucleus of the amygdala in mice. Eur. J. Neurosci. 39, 141-158. doi: 10.1111/ejn.12393

Haga, S., Hattori, T., Sato, T., Sato, K., Matsuda, S., Kobayakawa, R., et al. (2010). The male mouse pheromone ESP1 enhances female sexual receptive behaviour through a specific vomeronasal receptor. Nature 466, 118-122. doi: 10.1038/ nature09142

Haga-Yamanaka, S., Ma, L., He, J., Qiu, Q., Lavis, L. D., Looger, L. L., et al. (2014). Integrated action of pheromone signals in promoting courtship behavior in male mice. eLife 3:e03025. doi: 10.7554/eLife.03025
Chinese Academy of Sciences (No. XDB11010400), and the State Key Laboratory of Integrated Management of Pest Insects and Rodents (Chinese IPM1701). The funds received from the National Natural Science Foundation of China cover the open access publication fees.

\section{SUPPLEMENTARY MATERIAL}

The Supplementary Material for this article can be found online at: https://www.frontiersin.org/articles/10.3389/fncel. 2019.00455/full\#supplementary-material

Halem, H. A., Cherry, J. A., and Baum, M. J. (1999). Vomeronasal neuroepithelium and forebrain Fos responses to male pheromones in male and female mice. J. Neurobiol. 39, 249-263. doi: 10.1002/(SICI)1097-4695(199905)39:2<249:: AID-NEU9>3.0.CO;2-R

Halpern, M., and Martinez-Marcos, A. (2003). Structure and function of the vomeronasal system: an update. Prog. Neurobiol. 70, 245-318. doi: 10.1016/ s0301-0082(03)00103-5

Holy, T. E. (2018). The accessory olfactory system: innately specialized or microcosm of mammalian circuitry? Annu. Rev. Neurosci. 41, 501-525. doi: 10.1146/annurev-neuro-080317-061916

Honda, N., Sakamoto, H., Inamura, K., and Kashiwayanagi, M. (2008). Changes in Fos expression in the accessory olfactory bulb of sexually experienced male rats after exposure to female urinary pheromones. Eur. J. Neurosci. 27, 1980-1988. doi: 10.1111/j.1460-9568.2008.06169.x

Hurst, J. L., Payne, C. E., Nevison, C. M., Marie, A. D., Humphries, R. E., Robertson, D. H., et al. (2001). Individual recognition in mice mediated by major urinary proteins. Nature 414, 631-634. doi: 10.1038/414631a

Ishii, K. K., Osakada, T., Mori, H., Miyasaka, N., Yoshihara, Y., Miyamichi, K., et al. (2017). A labeled-line neural circuit for pheromone-mediated sexual behaviors in mice. Neuron 95:123-137.e8. doi: 10.1016/j.neuron.2017.05.038

Isogai, Y., Si, S., Pont-Lezica, L., Tan, T., Kapoor, V., Murthy, V. N., et al. (2011). Molecular organization of vomeronasal chemoreception. Nature 478, 241-245. doi: 10.1038/nature10437

Isogai, Y., Wu, Z., Love, M. I., Ahn, M. H., Bambah-Mukku, D., Hua, V., et al. (2018). Multisensory logic of infant-directed aggression by males. Cell 175:1827-1841.e17. doi: 10.1016/j.cell.2018.11.032

Jiang, Y., Gong, N. N., Hu, X. S., Ni, M. J., Pasi, R., and Matsunami, H. (2015). Molecular profiling of activated olfactory neurons identifies odorant receptors for odors in vivo. Nat. Neurosci. 18, 1446-1454. doi: 10.1038/nn.4104

Karlson, P., and Luscher, M. (1959). Pheromones': a new term for a class of biologically active substances. Nature $183,55-56$. doi: 10.1038/183055a0

Kaur, A. W., Ackels, T., Kuo, T. H., Cichy, A., Dey, S., Hays, C., et al. (2014). Murine pheromone proteins constitute a context-dependent combinatorial code governing multiple social behaviors. Cell 157, 676-688. doi: 10.1016/j.cell. 2014.02.025

Keverne, E. B. (1999). The vomeronasal organ. Science 286, 716-720. doi: 10.1126/ science.286.5440.716

Kim, S., Ma, L., Jensen, K. L., Kim, M. M., Bond, C. T., Adelman, J. P., et al. (2012). Paradoxical contribution of SK3 and GIRK channels to the activation of mouse vomeronasal organ. Nat. Neurosci. 15, 1236-1244. doi: 10.1038/nn.3173

Kimoto, H., Haga, S., Sato, K., and Touhara, K. (2005). Sex-specific peptides from exocrine glands stimulate mouse vomeronasal sensory neurons. Nature 437, 898-901. doi: 10.1038/nature04033

Kimoto, H., Sato, K., Nodari, F., Haga, S., Holy, T. E., and Touhara, K. (2007). Sexand strain-specific expression and vomeronasal activity of mouse ESP family peptides. Curr. Biol. 17, 1879-1884. doi: 10.1016/j.cub.2007.09.042

Kohl, J., Babayan, B. M., Rubinstein, N. D., Autry, A. E., Marin-Rodriguez, B., Kapoor, V., et al. (2018). Functional circuit architecture underlying parental behaviour. Nature 556, 326-331. doi: 10.1038/s41586-018-0027-0

Leinders-Zufall, T., Brennan, P., Widmayer, P., Maul-Pavicic, A., Jäger, M., Li, X.-H., et al. (2004). MHC class I peptides as chemosensory signals in the vomeronasal organ. Science 306, 1033-1037. doi: 10.1126/science.1102818 
Leinders-Zufall, T., Ishii, T., Chamero, P., Hendrix, P., Oboti, L., Schmid, A., et al. (2014). A family of nonclassical class I MHC genes contributes to ultrasensitive chemodetection by mouse vomeronasal sensory neurons. J. Neurosci. 34, 5121-5133. doi: 10.1523/JNEUROSCI.0186-14.2014

Leinders-Zufall, T., Lane, A. P., Puche, A. C., Ma, W., Novotny, M. V., Shipley, M. T., et al. (2000). Ultrasensitive pheromone detection by mammalian vomeronasal neurons. Nature 405, 792-796. doi: 10.1038/35015572

Li, Y., and Dulac, C. (2018). Neural coding of sex-specific social information in the mouse brain. Curr. Opin. Neurobiol. 53, 120-130. doi: 10.1016/j.conb.2018. 07.005

Li, Y., Mathis, A., Grewe, B. F., Osterhout, J. A., Ahanonu, B., Schnitzer, M. J., et al. (2017). Neuronal representation of social information in the medial amygdala of awake behaving mice. Cell 171:1176-1190.e17. doi: 10.1016/j.cell.2017.10.015

Liberles, S. D. (2014). Mammalian pheromones. Ann. Rev. Physiol. 76, 151-175. doi: 10.1146/annurev-physiol-021113-170334

Lin, D., Boyle, M. P., Dollar, P., Lee, H., Lein, E. S., Perona, P., et al. (2011). Functional identification of an aggression locus in the mouse hypothalamus. Nature 470, 221-226. doi: 10.1038/nature09736

Lischinsky, J. E., Sokolowski, K., Li, P., Esumi, S., Kamal, Y., Goodrich, M., et al. (2017). Embryonic transcription factor expression in mice predicts medial amygdala neuronal identity and sex-specific responses to innate behavioral cues. eLife 6:e21012. doi: 10.7554/eLife. 21012

Ma, L., Haga-Yamanaka, S., Yu, Q. E., Qiu, Q., Kim, S., and Yu, C. R. (2011). Imaging neuronal responses in slice preparations of vomeronasal organ expressing a genetically encoded calcium sensor. J. Vis. Exp. 6:3404. doi: 10. $3791 / 3404$

Martinez-Marcos, A., and Halpern, M. (1999). Differential projections from the anterior and posterior divisions of the accessory olfactory bulb to the medial amygdala in the opossum, Monodelphis domestica. Eur. J. Neurosci. 11, 3789-3799. doi: 10.1046/j.1460-9568.1999.00797.x

McElfresh, J. S., Hammond, A. M., and Millar, J. G. (2001). Sex pheromone components of the buck moth Hemileuca maia. J. Chem. Ecol. 27, 1409-1422.

Mohedano-Moriano, A., Pro-Sistiaga, P., Ubeda-Banon, I., Crespo, C., Insausti, R., and Martinez-Marcos, A. (2007). Segregated pathways to the vomeronasal amygdala: differential projections from the anterior and posterior divisions of the accessory olfactory bulb. Eur. J. Neurosci. 25, 2065-2080. doi: 10.1111/j. 1460-9568.2007.05472.x

Mohrhardt, J., Nagel, M., Fleck, D., Ben-Shaul, Y., and Spehr, M. (2018). Signal detection and coding in the accessory olfactory system. Chem. Senses 43, 667-695. doi: 10.1093/chemse/bjy061

Munger, S. D., Leinders-Zufall, T., and Zufall, F. (2009). Subsystem organization of the mammalian sense of smell. Ann. Rev. Physiol. 71, 115-140. doi: 10.1146/ annurev.physiol.70.113006.100608

Nodari, F., Hsu, F. F., Fu, X., Holekamp, T. F., Kao, L. F., Turk, J., et al. (2008), Sulfated steroids as natural ligands of mouse pheromone-sensing neurons. J. Neurosci. 28, 6407-6418. doi: 10.1523/JNEUROSCI.1425-08.2008

Novotny, M., Harvey, S., and Jemiolo, B. (1990). Chemistry of male dominance in the house mouse, Mus domesticus. Experientia 46, 109-113. doi: 10.1007/ bf01955433

Novotny, M. V. (2003). Pheromones, binding proteins and receptor responses in rodents. Biochem. Soc. Trans. 31, 117-122. doi: 10.1042/bst0310117

Novotny, M. V., Jemiolo, B., Wiesler, D., Ma, W., Harvey, S., Xu, F., et al. (1999). A unique urinary constituent, 6-hydroxy-6-methyl-3-heptanone, is a pheromone that accelerates puberty in female mice. Chem. Biol. 6, 377-383. doi: 10.1016/ S1074-5521(99)80049-0

Osakada, T., Ishii, K. K., Mori, H., Eguchi, R., Ferrero, D. M., Yoshihara, Y., et al. (2018). Sexual rejection via a vomeronasal receptor-triggered limbic circuit. Nat. Commun. 9:4463. doi: 10.1038/s41467-018-07003-5
Paxinos, G., and Franklin, K. B. J. (2004). The Mouse Brain in Stereotaxic Coordinates. Amsterdam: Elsevier Academic Press.

Riviere, S., Challet, L., Fluegge, D., Spehr, M., and Rodriguez, I. (2009). Formyl peptide receptor-like proteins are a novel family of vomeronasal chemosensors. Nature 459, 574-577. doi: 10.1038/nature08029

Rodriguez, I., Feinstein, P., and Mombaerts, P. (1999). Variable patterns of axonal projections of sensory neurons in the mouse vomeronasal system. Cell 97, 199-208. doi: 10.1016/s0092-8674(00)80730-8

Stowers, L., Holy, T. E., Meister, M., Dulac, C., and Koentges, G. (2002). Loss of sex discrimination and male-male aggression in mice deficient for TRP2. Science 295, 1493-1500. doi: 10.1126/science.1069259

Sturm, T., Leinders-Zufall, T., Macek, B., Walzer, M., Jung, S., Pommerl, B., et al. (2013). Mouse urinary peptides provide a molecular basis for genotype discrimination by nasal sensory neurons. Nat. Commun. 4:1616. doi: 10.1038/ ncomms 2610

Szymanski, L. A., and Keller, M. (2014). Activation of the olfactory system in response to male odors in female prepubertal mice. Behav. Brain Res. 271(Suppl. C), 30-38. doi: 10.1016/j.bbr.2014.05.051

Touhara, K., and Vosshall, L. B. (2009). Sensing odorants and pheromones with chemosensory receptors. Ann. Rev. Physiol. 71, 307-332. doi: 10.1146/annurev. physiol.010908.163209

Wagner, S., Gresser, A. L., Torello, A. T., and Dulac, C. (2006). A multireceptor genetic approach uncovers an ordered integration of VNO sensory inputs in the accessory olfactory bulb. Neuron 50, 697-709. doi: 10.1016/j.neuron.2006. 04.033

Wei, Y.-C., Wang, S.-R., Jiao, Z.-L., Zhang, W., Lin, J.-K., Li, X.-Y., et al. (2018). Medial preoptic area in mice is capable of mediating sexually dimorphic behaviors regardless of gender. Nat. Commun. 9:279. doi: 10.1038/s41467-01702648-0

Wu, Z., Autry, A. E., Bergan, J. F., Watabe-Uchida, M., and Dulac, C. G. (2014). Galanin neurons in the medial preoptic area govern parental behaviour. Nature 509, 325-330. doi: 10.1038/nature13307

Xu, P. S., Lee, D., and Holy, T. E. (2016). Experience-dependent plasticity drives individual differences in pheromone-sensing neurons. Neuron 91, 878-892. doi: 10.1016/j.neuron.2016.07.034

Young, J. M., Massa, H. F., Hsu, L., and Trask, B. J. (2010). Extreme variability among mammalian V1R gene families. Genome Res. 20, 10-18. doi: 10.1101/gr. 098913.109

Young, J. M., and Trask, B. J. (2007). V2R gene families degenerated in primates, dog and cow, but expanded in opossum. Trends Genet. 23, 212-215. doi: 10. 1016/j.tig.2007.03.004

Zhang, J.-X., Liu, Y.-J., Zhang, J.-H., and Sun, L. (2008). Dual role of preputial gland secretion and its major components in sex recognition of mice. Physiol. Behav. 95, 388-394. doi: 10.1016/j.physbeh.2008.07.002

Zhang, X., Rodriguez, I., Mombaerts, P., and Firestein, S. (2004). Odorant and vomeronasal receptor genes in two mouse genome assemblies. Genomics 83 , 802-811. doi: 10.1016/j.ygeno.2003.10.009

Conflict of Interest: The authors declare that the research was conducted in the absence of any commercial or financial relationships that could be construed as a potential conflict of interest.

Copyright (c) 2019 Liu, Zhang, Wang, Guo, Wu, Zhang and Huang. This is an open-access article distributed under the terms of the Creative Commons Attribution License (CC BY). The use, distribution or reproduction in other forums is permitted, provided the original author(s) and the copyright owner(s) are credited and that the original publication in this journal is cited, in accordance with accepted academic practice. No use, distribution or reproduction is permitted which does not comply with these terms. 